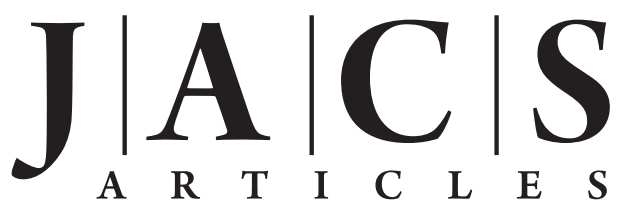

Published on Web 06/10/2010

\title{
Identifying Diversity in Nanoscale Electrical Break Junctions
}

\author{
Santiago Martín, ${ }^{\dagger, l}$ lain Grace, ${ }^{\ddagger}$ Martin R. Bryce, ${ }^{\star, \S}$ Changsheng Wang, ${ }^{\S}$ \\ Rukkiat Jitchati, ${ }^{\S, \perp}$ Andrei S. Batsanov, ${ }^{\S}$ Simon J. Higgins, ${ }^{\dagger}$ Colin J. Lambert, ${ }^{*}{ }^{\ddagger}$ and \\ Richard J. Nichols ${ }^{\star, \dagger}$ \\ Centre for Nanoscale Science and Department of Chemistry, University of Liverpool, \\ Liverpool L69 7ZD, U.K., Department of Physics, Lancaster University, \\ Lancaster LA1 4YB, U.K., Department of Chemistry and Centre for Molecular and Nanoscale \\ Electronics, Durham University, Durham DH1 3LE, U.K., Departamento de Química \\ Orgánica-Química Física, Facultad de Ciencias, Universidad de Zaragoza, 50009 Zaragoza, Spain, \\ and Advanced Organic Materials and Devices Laboratory, Department of Chemistry, Faculty of \\ Science, Ubon Ratchathani University, Warinchumrap, Ubon Ratchathani 34190, Thailand
}

Received April 20, 2010; E-mail: r.j.nichols@liverpool.ac.uk; m.r.bryce@durham.ac.uk; c.lambert@lancaster.ac.uk

\begin{abstract}
The realization of molecular-scale electronic devices will require the development of novel strategies for controlling electrical properties of metallmoleculelmetal junctions, down to the single molecule level. Here, we show that it is possible to exert chemical control over the formation of metallmolecule...moleculelmetal junctions in which the molecules interact by $\pi$-stacking. The tip of an STM is used to form one contact, and the substrate the other; the molecules are conjugated oligophenyleneethynylenes (OPEs). Supramolecular $\pi-\pi$ interactions allow current to flow through the junction, but not if bulky tert-butyl substituents on the phenyl rings prevent such interactions. For the first time, we find evidence that $\pi$-stacked junctions can form even for OPEs with two thiol contacts. Furthermore, we find evidence for metallmoleculelmetal junctions involving oligophenyleneethynylene monothiols, in which the second contact must be formed by the interaction of the $\pi$-electrons of the terminal phenyl ring with the metal surface.
\end{abstract}

\section{Introduction}

The feat of trapping single molecules within contact junctions can be achieved through a number of techniques which utilize scanning probe microscopes, ${ }^{1-6}$ break junctions, ${ }^{7-13}$ litho-

Department of Chemistry, University of Liverpool.

Department of Physics, Lancaster University.

$\S$ Department of Chemistry, Durham University.

"Departamento de Quimica Organica-Quimica Fisica, Zaragoza University.

${ }^{\perp}$ Department of Chemistry, Ubon Ratchathani University.

(1) Xu, B. Q.; Tao, N. J. J. Science 2003, 301, 1221-1223.

(2) Cui, X. D.; Primak, A.; Zarate, X.; Tomfohr, J.; Sankey, O. F.; Moore, A. L.; Moore, T. A.; Gust, D.; Harris, G.; Lindsay, S. M. Science 2001, 294, 571-574.

(3) Kubatkin, S.; Danilov, A.; Hjort, M.; Cornil, J.; Bredas, J. L.; StuhrHansen, N.; Hedegard, P.; Bjornholm, T. Nature 2003, 425, 698701.

(4) Haiss, W.; van Zalinge, H.; Higgins, S. J.; Bethell, D.; Hobenreich, H.; Schiffrin, D. J.; Nichols, R. J. J. Am. Chem. Soc. 2003, 125, 15294 15295.

(5) Haiss, W.; Nichols, R. J.; van Zalinge, H.; Higgins, S. J.; Bethell, D.; Schiffrin, D. J. Phys. Chem. Chem. Phys. 2004, 6, 4330-4337.

(6) Tao, N. J. Nat. Nanotechnol. 2006, 1, 173-181.

(7) Reed, M. A.; Zhou, C.; Muller, C. J.; Burgin, T. P.; Tour, J. M. Science 1997, 278, 252-254.

(8) Weber, H. B.; Reichert, J.; Weigend, F.; Ochs, R.; Beckmann, D.; Mayor, M.; Ahlrichs, R.; von Lohneysen, H. Chem. Phys. 2002, 281, $113-125$.

(9) Smit, R. H. M.; Noat, Y.; Untiedt, C.; Lang, N. D.; van Hemert, M. C.; van Ruitenbeek, J. M. Nature 2002, 419, 906-909.

(10) Gonzalez, M. T.; Wu, S. M.; Huber, R.; van der Molen, S. J.; Schonenberger, C.; Calame, M. Nano Lett. 2006, 6, 2238-2242.

(11) Venkataraman, L.; Klare, J. E.; Nuckolls, C.; Hybertsen, M. S.; Steigerwald, M. L. Nature 2006, 442, 904-907. graphically defined nanogaps, ${ }^{3,14}$ or chemical synthesis of nanoscale structures bridged by target molecules. ${ }^{15}$ The molecules investigated have increased in sophistication lately, to encompass "longer" molecular bridges of organic or metalorganic oligomers, ${ }^{6,16-21}$ supramolecular interactions such as double-stranded DNA, ${ }^{22-26}$ noncovalent bonding of individual

(12) Huber, R.; Gonzalez, M. T.; Wu, S.; Langer, M.; Grunder, S.; Horhoiu, V.; Mayor, M.; Bryce, M. R.; Wang, C. S.; Jitchati, R.; Schonenberger, C.; Calame, M. J. Am. Chem. Soc. 2008, 130, 1080-1084.

(13) Kergueris, C.; Bourgoin, J. P.; Palacin, S.; Esteve, D.; Urbina, C.; Magoga, M.; Joachim, C. Phys. Rev. B 1999, 59, 12505-12513.

(14) Osorio, E. A.; Bjornholm, T.; Lehn, J. M.; Ruben, M.; van der Zant, H. S. J. J. Phys.: Condens. Matter 2008, 20, 374121.

(15) Champagne, A. R.; Pasupathy, A. N.; Ralph, D. C. Nano Lett. 2005, $5,305-308$.

(16) Sedghi, G.; Sawada, K.; Esdaile, L. J.; Hoffmann, M.; Anderson, H. L.; Bethell, D.; Haiss, W.; Higgins, S. J.; Nichols, R. J. J. Am. Chem. Soc. 2008, 130, 8582-8583.

(17) Wang, C. S.; Batsanov, A. S.; Bryce, M. R.; Martin, S.; Nichols, R. J.; Higgins, S. J.; Garcia-Suarez, V. M.; Lambert, C. J. J. Am. Chem. Soc. 2009, 131, 15647-15654.

(18) Wu, S. M.; Gonzalez, M. T.; Huber, R.; Grunder, S.; Mayor, M.; Schonenberger, C.; Calame, M. Nat. Nanotechnol. 2008, 3, 569-574.

(19) Yamada, R.; Kumazawa, H.; Noutoshi, T.; Tanaka, S.; Tada, H. Nano Lett. 2008, 8, 1237-1240.

(20) Leary, E.; Van Zalinge, H.; Higgins, S. J.; Nichols, R. J.; de Biani, F. F.; Leoni, P.; Marchetti, L.; Zanello, P. Phys. Chem. Chem. Phys. 2009, 11, 5198-5202.

(21) Mayor, M.; von Hanisch, C.; Weber, H. B.; Reichert, J.; Beckmann, D. Angew. Chem., Int. Ed. 2002, 41, 1183-1186.

(22) Xu, B. Q.; Zhang, P. M.; Li, X. L.; Tao, N. J. Nano Lett. 2004, 4, $1105-1108$. 
Chart 1. Compounds Featured in This Work (1, 2, 4, and 5) and That of Haiss et al. ${ }^{28}$ (1) and Wu et al. ${ }^{18}$ (3 and 6) (Acetyl Protecting Groups on the Sulfur Atoms Have Been Omitted for Clarity)

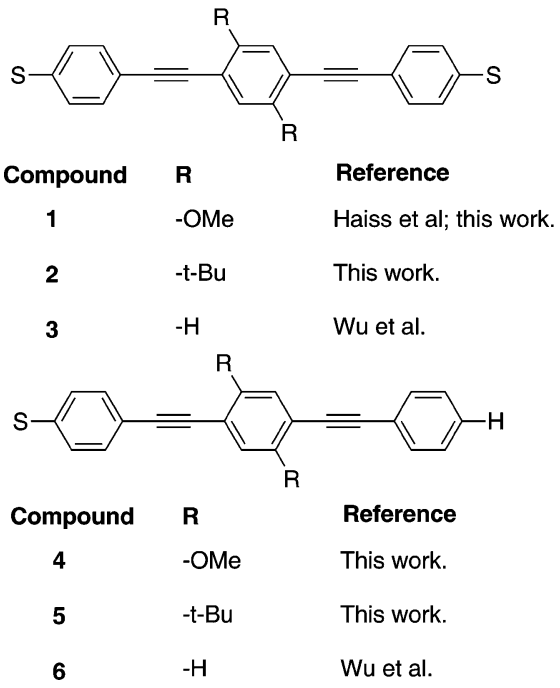

base pairs across metallic gaps, ${ }^{27}$ and the interaction of aromatic molecules via $\pi$-stacking. ${ }^{18}$ Understanding and controlling intermolecular interactions is an important step toward using individual molecules or supramolecular assemblies as building blocks for electronic devices. Wu et al. recently made the landmark discovery of the formation of electrical junctions through $\pi$-stacking of adjacent molecules in mechanically formed break junctions. ${ }^{18}$ They reported conductance data for pairs of oligophenyleneethynylene (OPE) molecular "rods" interacting through $\pi-\pi$ interactions to bridge nanoscale gaps between gold electrical contacts. In OPE molecules with thiol groups at both ends $(\mathrm{S}-\mathrm{OPE}-\mathrm{S})$, the molecular bridges featured $\mathrm{Au}-\mathrm{S}$ chemisorption at both contacts with a single clear conductance histogram peak attributed to single AulS-OPE-SIAu junctions. Using analogous molecules with a single thiol terminus (S-OPE) led to replacement of this histogram peak by another peak of considerably lower conductance. ${ }^{18}$ This was attributed to a pair of S-OPE molecules, adsorbed at the adjacent gold contacts and interacting by $\pi$-stacking, resulting in a correspondingly longer bridge length and lower conductance. Furthermore, they showed that formation of these bridges was efficient for OPEs with three phenylene groups but markedly less defined for OPEs with two phenylene groups. ${ }^{18}$ This demonstrates that a sufficient footprint of overlap is necessary for effective $\pi$-stacking.

In this manuscript, we address the formation of junctions using molecules (Chart 1) in which the ability to $\pi$-stack is chemically controlled through the use of bulky side groups that prevent efficient intermolecular overlap. This approach aids in the assignment of histogram features to $\pi$-stacking. We further demonstrate the competitive formation of both $\pi$-stacked junctions and "conventional" single AulS-OPE-SIAu junctions

(23) van Zalinge, H.; Schiffrin, D. J.; Bates, A. D.; Haiss, W.; Ulstrup, J.; Nichols, R. J. ChemPhysChem 2006, 7, 94-98.

(24) Cohen, H.; Nogues, C.; Naaman, R.; Porath, D. Proc. Natl. Acad. Sci. U.S.A. 2005, 102, 11589-11593.

(25) Cohen, H.; Nogues, C.; Ullien, D.; Daube, S.; Naaman, R.; Porath, D. Faraday Discuss. 2006, 131, 367-376.

(26) Ullien, D.; Cohen, H.; Porath, D. Nanotechnology 2007, 18, 424015

(27) Chang, S. A.; He, J.; Lin, L. S.; Zhang, P. M.; Liang, F.; Young, M.; Huang, S.; Lindsay, S. Nanotechnology 2009, 20, 185102. for $\mathrm{S}-\mathrm{OPE}-\mathrm{S}$ molecules. The latter observation demonstrates that care is needed when assigning conductance histogram features. To aid in the attribution of conductance histogram peaks to these different junction types, we have used measurements of the statistical distribution of break-off distances (the distance at which junctions are pulled apart during repeated STM retraction experiments). Our measurements have also allowed us to assign a previously uncharacterized conductance histogram feature to a new type of single molecule junction configuration in which the phenyl end of an OPE monothiol (S-OPE) is directly contacted to gold. DFT and transport computations give further insights into electronic transmission through these novel structures.

\section{Experimental and Theoretical Methods}

Synthesis. Molecule 1 was available from an earlier study, ${ }^{28}$ and $\mathbf{2}, \mathbf{4}$, and $\mathbf{5}$ were synthesized and characterized as described in the Supporting Information.

Conductance Measurements. An Agilent STM running Picoscan 4.19 Software was used for all single molecule conductance measurements which were performed at room temperature in air. Molecular adlayers were formed on $\mathrm{Au}(111)$ substrates. These substrates were formed from commercially available gold on glass samples with a chromium adhesive layer (Arrandee) which were flame annealed immediately prior to use. Flame annealing involved heating the gold slide until it took on a slight orange hue. It was then kept in this state for approximately $30 \mathrm{~s}^{-1} \mathrm{~min}$, but care was taken to ensure that the sample did not overheat. Molecular adsorption was achieved by immersing the electrode for $30 \mathrm{~s}$ in 5 $\times 10^{-5} \mathrm{M}$ THF solutions. The sample was then rinsed in ethanol and gently blown dry in a stream of nitrogen gas. Gold STM tips were fabricated from $0.25 \mathrm{~mm} \mathrm{Au}$ wire $(99.99 \%)$ which was freshly electrochemically etched for each experiment at $+2.4 \mathrm{~V}$ in a mixture of ethanol $(50 \%)$ and $\mathrm{HCl}(50 \%)$.

Electrical measurements were performed using an STM and the $I(s)$ method, described in detail previously. ${ }^{4,17,28,29}$ In brief, this method involves the repeated formation and cleavage of molecular bridges generally formed between gold contacts (a Au STM tip and a Au substrate). In the $I(s)$ technique the electrical conductance of the junction is measured as the molecule is fully extended in the gap between STM-tip and substrate as the tip is rapidly retracted. Current steps are seen in the retraction process which are taken to be characteristic of the cleavage of Aulmolecule(s)|Au electrical junctions. ${ }^{4}$ The height of these current steps is repeatedly measured, and the resulting current step heights are then plotted in a conductance histogram. In this work we have performed $I(s)$ scans from the position defined by the set-point values of tunneling current $\left(I_{0}\right)$ and tunneling voltage $\left(U_{\mathrm{t}}\right)$ to a distance of $+2.5 \mathrm{~nm}$ with a scan rate of $25 \mathrm{~nm} \mathrm{~s}^{-1}$. Since the histogram peaks span a relatively wide range, to optimize observation we have recorded data using both low and high current preamplifiers (see Results and Discussion and Supporting Information). The voltage to length conversion factor of the STM was calibrated using images of Au(111) monatomic steps $(0.235 \mathrm{~nm}$ height $)$ while the low and high current preamplifiers were calibrated using resistors.

Conductance histograms were constructed from the currentdistance curves by adding all the current data from $\sim 450 I(s)$ curves showing discernible plateaus. Typically, in a data collection series for a given target molecule more than $5500 I(s)$ scans were recorded. Since only a fraction of the $I(s)$ scans resulted in AulmoleculelAu electrical junction formation, curves not symptomatic of junction formation, including those with an exponential decay characteristic

(28) Haiss, W.; Wang, C. S.; Grace, I.; Batsanov, A. S.; Schiffrin, D. J.; Higgins, S. J.; Bryce, M. R.; Lambert, C. J.; Nichols, R. J. Nat. Mater. 2006, 5, 995-1002.

(29) Haiss, W.; Martin, S.; Scullion, L. E.; Bouffier, L.; Higgins, S. J.; Nichols, R. J. Phys. Chem. Chem. Phys. 2009, 11, 10831-10838. 
of tunneling, were rejected from histogram analysis. The probability of forming molecular junctions is lower with the $I(s)$ technique than the in situ BJ technique, since the former avoids metallic contact between the tip and substrate; a comparative study had indicated that avoiding tip-surface metallic contact promotes observation of the lower conductance group. ${ }^{30}$ Conductance histograms are presented in units of the conductance quantum $G_{0}$ $=2 e^{2} / h=77.4 \mu \mathrm{S}$ and errors are evaluated by fitting histogram peaks with Gaussian curves.

In this study, the determination of "break-off distance" is important in the assignment of histogram peaks. ${ }^{17,28-30}$ "Breakoff distance" refers to the estimated separation at which the molecular junction cleaves during an $I(s)$ retraction experiment. Cleavage is either at the $\mathrm{Au}$-molecule contact or between the contact surface atoms themselves ( $\mathrm{Au}-\mathrm{Au}$ bonds). ${ }^{31,32}$ By calibrating the tip-to-sample distance an assessment of the break-off distance can be made which can help to distinguish $\pi$-stacked junctions from other junction configurations. Full details are given in the Supporting Information.

Theoretical Methods. The electronic and transport properties of the molecules in Chart 1 contacted between gold leads were calculated with the $a b$ initio transport code SMEAGOL. ${ }^{33}$ This method uses the Hamiltonian provided by the density functional theory code SIESTA ${ }^{34}$ to obtain the zero bias electron transmission coefficients. To begin with, the relaxed geometry of the molecule was calculated; here we used a double- $\zeta$ polarized basis set, an energy cutoff of 150 Ry to define the real space grid, and the local density approximation ${ }^{35}$ to calculate exchange and correlation energy. The molecular coordinates were relaxed until all forces were $<0.02 \mathrm{eV} / \AA$. For the conductance calculations, the molecules were extended between $\mathrm{Au}(111)$ leads; nine atoms per layer were used, and six layers of gold were enough to converge the transmission. To model the asymmetry of the STM junction, a flat surface was used for the bottom electrode contact and a pyramid of gold atoms for the top electrode (e.g., Figure 3), with the terminal thiol binding to the tip atom. For the junctions containing two molecules, we calculated the optimal "stacking" geometry by minimizing the ground state energy by varying the overlap length $X$ and the separation distance $D$ (Figure 5; more details of the theoretical approach can be found in the Supporting Information).

\section{Results and Discussion}

Molecules employed in, or of relevance to, this study are shown in Chart 1. Compound $\mathbf{1}$ is the "reference" compound for our current investigation. It featured previously in a publication by Haiss et al. ${ }^{28}$ and was characterized as having a conductance of $2 \mathrm{nS}$ when untilted in a contact junction with gold leads. Compound $\mathbf{2}$ has bulky tert-butyl substituents, designed to prevent $\pi$-stacking. Compound $\mathbf{3}$ is analogous to $\mathbf{1}$ and was studied by $\mathrm{Wu}$ et al. ${ }^{18}$ Compounds $4-6$ have a single thiol contact. In the seminal study by $\mathrm{Wu}$ et al., ${ }^{18}$ it was found that molecules with two contacting groups such as $\mathbf{3}$ formed single molecule junctions with chemisorption at both gold contacts, whereas monothiols such as $\mathbf{6}$ formed junctions in which the metal contacts were bridged by two $\pi$-stacked molecules.

(30) Haiss, W.; Martin, S.; Leary, E.; van Zalinge, H.; Higgins, S. J.; Bouffier, L.; Nichols, R. J. J. Phys. Chem. C 2009, 113, 5823-5833.

(31) Xu, B. Q.; Xiao, X. Y.; Tao, N. J. J. Am. Chem. Soc. 2003, 125, 16164-16165.

(32) Rubio-Bollinger, G.; Bahn, S. R.; Agrait, N.; Jacobsen, K. W.; Vieira, S. Phys. Rev. Lett. 2001, 87, 026101.

(33) Soler, J. M.; Artacho, E.; Gale, J. D.; Garcia, A.; Junquera, J.; Ordejon, P.; Sanchez-Portal, D. J. Phys.: Condens. Matter 2002, 14, 27452779.

(34) Rocha, A. R.; Garcia-Suarez, V. M.; Bailey, S.; Lambert, C.; Ferrer, J.; Sanvito, S. Phys. Rev. B 2006, 73, 085414.

(35) Perdew, J. P.; Zunger, A. Phys. Rev. B 1981, 23, 5048-5079.

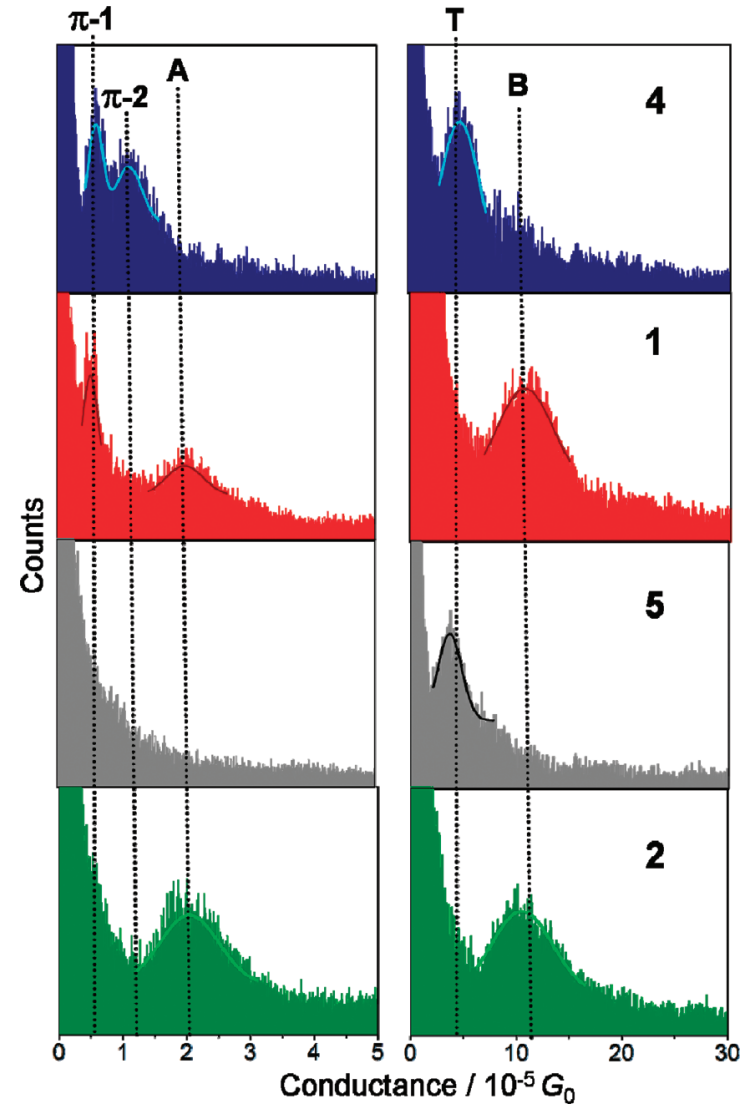

Figure 1. Conductance histograms for compounds $4,1,5,2$ recorded at low set-point current ( $5 \mathrm{nA}$, left panel), using a low current amplifier, and high set-point current (60 nA, right panel), using a high current amplifier, respectively. Conductance data are presented in units of the conductance quantum $G_{0}=2 e^{2} / h=77.4 \mu \mathrm{S} . U_{\mathrm{t}}=0.6 \mathrm{~V}$.

In this study, we analyze conductance data for compounds 1, 2, 4, and 5. The molecules have been chosen to aid the assignment of multiple peaks occurring in conductance histograms to differing junction configurations. The monothiolated derivatives (4 and 5) are chosen to exclude the formation of AulS-OPE-SIAu single molecule junctions, while the sterically hindered derivatives ( $\mathbf{2}$ and $\mathbf{5}$ ) are chosen to impede $\pi$-stacking. This, together with statistical analysis of the distance at which junctions cleave, aids in the assignment of the measured conductance histograms. In what follows, we use the $I(s)$ method for conductance determination. ${ }^{4,17,28,29}$ In this method, a Au STM tip is brought close to a $\mathrm{Au}(111)$ surface controlled by the set-point current $I_{0}$, on which is adsorbed a low (submonolayer) coverage of the target molecules. The feedback loop is switched off and the tip is withdrawn while the tunneling current is measured. The current-vertical distance $I(s)$ curves are then analyzed statistically via histogram plots to determine the electrical properties of the molecular junctions. This method has the advantage that it is possible, by careful calibration, to measure simultaneously both the tunneling current $I$ and the tip height at which the junction breaks down (either by $\mathrm{Au}-\mathrm{S}$ or by $\mathrm{Au}-\mathrm{Au}$ bond cleavage) which we label $s_{\text {break-off }}$ (see the Method section and the Supporting Information for full details).

Figure 1 shows the conductance histograms for compounds $\mathbf{1}, \mathbf{2}, \mathbf{4}$, and $\mathbf{5}$. The left panel shows data recorded with the low current amplifier and low set-point current $\left(I_{0}\right)$ values $\left(I_{0}=5\right.$ $\mathrm{nA}$ and $\left.U_{\mathrm{t}}=0.6 \mathrm{~V}\right)$. The right panel shows data recorded with a high current (lower sensitivity) amplifier at higher set-point currents $\left(I_{0}=60 \mathrm{nA}\right.$ and $\left.U_{\mathrm{t}}=0.6 \mathrm{~V}\right)$. The choice of low or 
high current amplifiers enables the observation of either lower or higher conductance peaks. In particular, the choice of low current amplifier and low set-point currents effectively restricts observation to events (current jumps in $I(s)$ curves) at the low conductance range $\left(<4 \times 10^{-5} G_{0}\right)$. This choice of low current amplifier and low set-point current could be viewed, by way of an analogy, as low pass filtering of the data, since it restricts observations to low-current events at high sensitivity. The high current amplifier used at higher set-point currents, on the other hand, can be viewed as high pass removal of the low current events that are "lost" in the background appearing near the ordinate. By using this combination of low and high current amplifiers a greater range of conductance histogram peaks can be measured with high sensitivity.

Guide lines are provided in Figure 1 to highlight common features between histograms. Starting with the low current amplifier data, the compounds without the sterically blocking tert-butyl substituents ( $\mathbf{1}$ and $\mathbf{4}$ ) feature a peak labeled $\boldsymbol{\pi}-\mathbf{1}$ which is attributed to the formation of Aulmolecule...moleculelAu junctions in which the molecules $\pi$-stack (vide infra). The histogram of $\mathbf{4}$ shows a shoulder on this peak (labeled $\boldsymbol{\pi}$-2; although $\boldsymbol{\pi - 2}$ is not clearly apparent for $\mathbf{1}$ where its appearance may be masked by an adjacent higher conductance and more intense peak marked A). Note that these $\pi$-peaks do not appear for compounds $\mathbf{2}$ and $\mathbf{5}$, which have the sterically blocking tertbutyl substituents. This leads to the conclusion that the $\pi$-peaks do indeed arise from $\pi$-stacking, in agreement with the previous recognition of $\pi$-stacking in OPE derivatives by Wu et al. ${ }^{18}$ However, a glance at our overall conductance histogram data shows marked differences as well, in that we observe for certain derivatives the resolution of multiple distinctive conductance peaks.

In the low current amplifier data for $\mathbf{1}$ (Figure 1, left panel), a peak marked $\mathbf{A}$ at higher conductance values than the $\pi$-peak is seen. This peak is not apparent for compounds $\mathbf{4}$ and $\mathbf{5}$, the monothiol analogues, but it is also present for the other dithiol analogue 2. This leads us to attribute the A peak to AulS$\mathrm{OPE}-\mathrm{S} \mid \mathrm{Au}$ single molecule junctions with chemisorbed $\mathrm{Au}-\mathrm{S}$ contacts at both ends of the molecular bridge. We show later in the text that the break-off distance for these $\mathbf{A}$ features is consistent with the expected length of a AulS-OPE-SIAu junction, while the $\pi$-peaks feature considerably longer breakoff lengths. Histograms for $\mathbf{5}$ (monothiol and tert-butyl groups) feature neither $\mathbf{A}$ nor $\pi$-peaks, while histograms for $\mathbf{2}$ feature only A peaks.

We now turn to the high current amplifier data (Figure 1, right panel). Two histogram peaks are observed in this range, and these are marked with the dashed guidelines as " $\mathbf{T}$ " and "B", respectively. Peak B appears only for the dithiolated analogues (1 and 2) and is assigned, like the $\mathbf{A}$ peaks, to AulS-OPE-SIAu single molecule junctions, albeit with a higher conductance than the A peaks. Molecules $\mathbf{4}$ and $\mathbf{5}$ will not be able to form such AulS-OPE-SIAu junctions, since they are monothiols, and this is consistent with the absence of both $\mathbf{A}$ and $\mathbf{B}$ peaks for these molecules. It has been previously shown that AulS-backbone-SIAu junctions exhibit different conductance groups which have been related to different adsorption geometries/conformations of the sulfur chemisorbed at the gold contacts. ${ }^{5,30,36-38}$ It appears likely that a similar phenomenon

(36) Li, C.; Pobelov, I.; Wandlowski, T.; Bagrets, A.; Arnold, A.; Evers, F. J. Am. Chem. Soc. 2008, 130, 318-326.

(37) Li, X. L.; He, J.; Hihath, J.; Xu, B. Q.; Lindsay, S. M.; Tao, N. J J. Am. Chem. Soc. 2006, 128, 2135-2141.

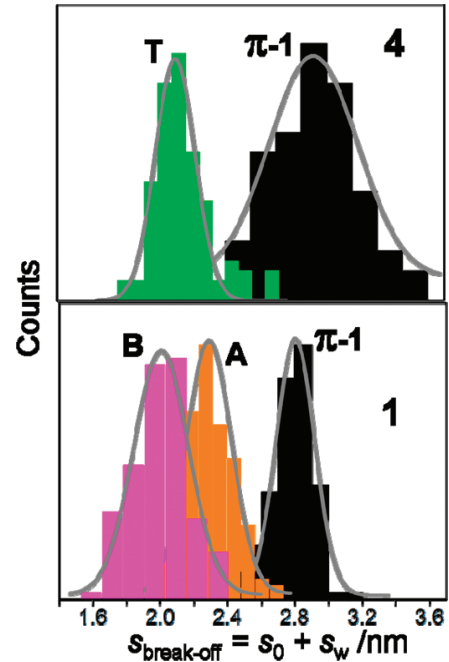

Figure 2. Break-off distance histograms for $\mathbf{4}$ (top) and $\mathbf{1}$ (bottom), for the $\mathbf{T}$ and $\boldsymbol{\pi}-\mathbf{1}$ peaks (compound $\mathbf{4}$ ), and for the $\mathbf{A}, \mathbf{B}$ and $\boldsymbol{\pi}-\mathbf{1}$ peaks (compound 1).

is occurring here for the OPE derivatives. However, what is surprising is the appearance of an additional peak labeled " $\mathbf{T}$ " for the two monothiol compounds (4 and 5). Break-off distance data (vide infra: Figure 2) show this peak to be consistent with junctions of a single molecule length (rather than $\pi$-stacked junctions). However, since both $\mathbf{4}$ and $\mathbf{5}$ are monothiols, we infer that this peak arises from the end phenyl group making direct physical contact with a gold lead and forming one end of the electrical junction. Such junctions have not been identified clearly at the single molecule level before, but contacts of this nature could be formed in larger area junctions in which monothiols are sandwiched between a pair of closely spaced metal contacts. ${ }^{39-43}$ The direct interaction of benzene with platinum contacts in an STM configuration has also been reported by Kiguchi et al., with the formation of PtlbenzenelPt junctions (benzene sandwiched "face-on" between two Pt leads) with high conductance. ${ }^{44}$

In the discussion above, break-off distance determinations have been referred to as an aid to peak assignment. This important information is not available from the MCBJ experiments of $\mathrm{Wu}$ et al. ${ }^{18}$ and is an added advantage of using the $I(s)$ technique to study these systems. These are now discussed in more detail (see Supporting Information to obtain more information about the determination of $s_{\text {break-off }}$ histograms). Figure 2 shows break-off distance histograms for $\mathbf{4}$ that feature the $\boldsymbol{\pi}$ and $\mathbf{T}$ group conductance peaks. The $\pi$-peak is characterized by a break-off distance of $2.9 \pm 0.3 \mathrm{~nm}$, which is considerably longer than a fully extended junction containing a single $\mathbf{4}$ molecule $(2.19 \mathrm{~nm})$, while the $\mathbf{T}$-peak has a much

(38) Zhou, J. F.; Chen, F.; Xu, B. Q. J. Am. Chem. Soc. 2009, 131, 1043910446.

(39) Cui, X. D.; Zarate, X.; Tomfohr, J.; Sankey, O. F.; Primak, A.; Moore, A. L.; Moore, T. A.; Gust, D.; Harris, G.; Lindsay, S. M. Nanotechnology 2002, 13, 5-14.

(40) Beebe, J. M.; Kim, B.; Frisbie, C. D.; Kushmerick, J. G. ACS Nano 2008, 2, 827-832.

(41) Wold, D. J.; Frisbie, C. D. J. Am. Chem. Soc. 2001, 123, 5549-5556.

(42) Ishida, T.; Mizutani, W.; Akiba, U.; Umemura, K.; Inoue, A.; Choi, N.; Fujihira, M.; Tokumoto, H. J. Phys. Chem. B 1999, 103, 16861690.

(43) Kushmerick, J. G.; Whitaker, C. M.; Pollack, S. K.; Schull, T. L.; Shashidhar, R. Nanotechnology 2004, 15, S489-S493.

(44) Kiguchi, M.; Murakoshi, K. Thin Solid Films 2009, 518, 466-469. 
Table 1. Tabulated Experimental and Theoretical Data for Compounds 4, 1, 2, and $5^{a}$

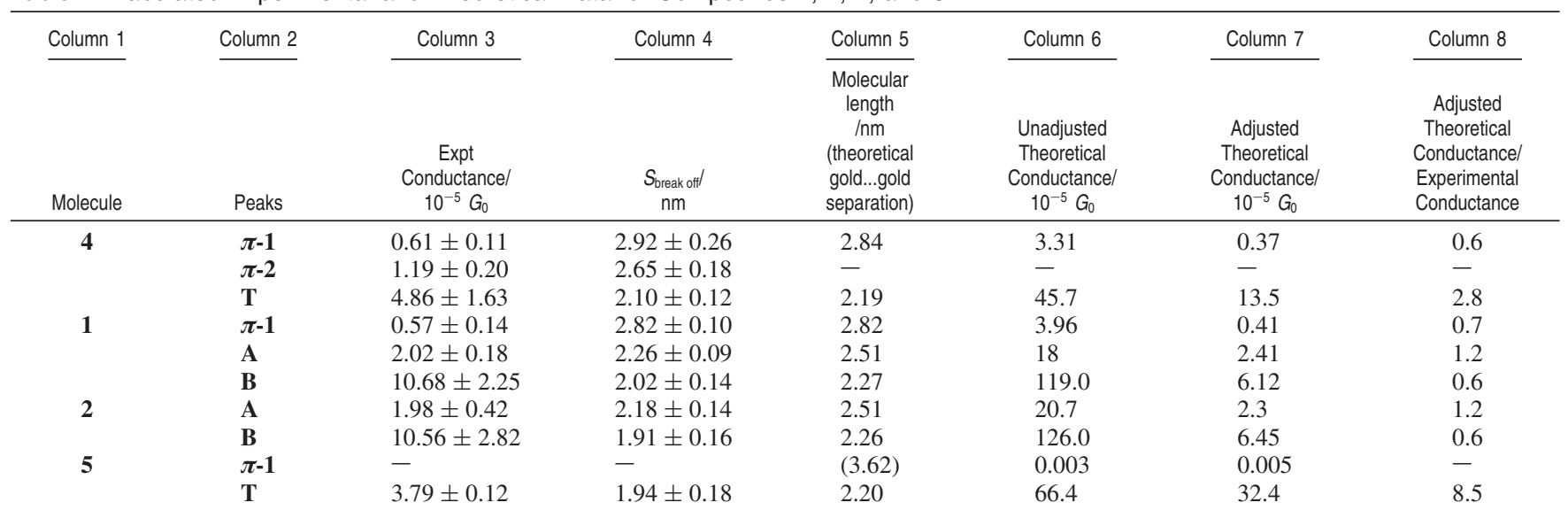

${ }^{a}$ Column 2: conductance peak label (see text for a description). Column 3: conductance measured from experimental histograms. Column 4: experimentally measured break-off distance from calibrated break-off distance measurements. Column 5: the theoretical Au...Au contact separation for the molecule(s) extended in the junction for this configuration. Column 6: The unadjusted theoretically computed conductance. Column 7: the adjusted theoretically computed conductance (see text). Column 8: The ratio of column 7 (adjusted theoretical values) to column 3 (experimental values).
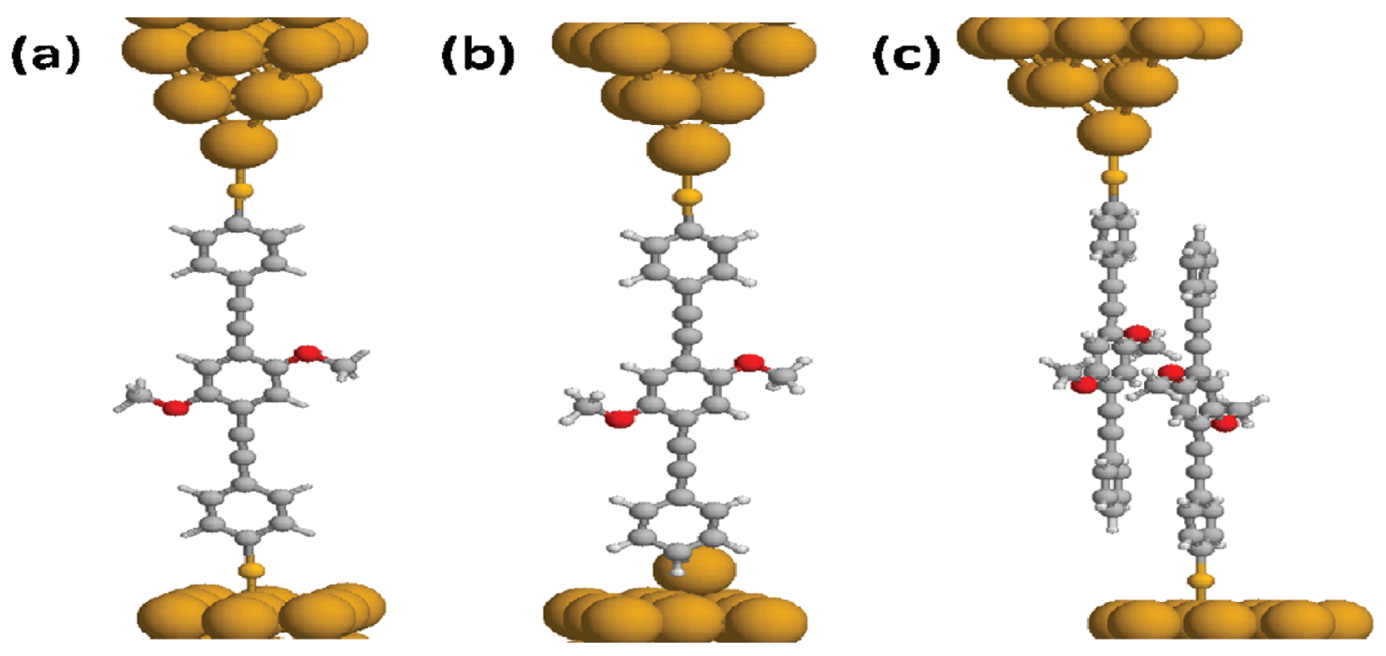

Figure 3. Models of the considered junction configurations for the A peak of compound $\mathbf{1}$ (a), the $\mathbf{T}$ peak of compound $\mathbf{4}$ (b), and the $\boldsymbol{\pi}$-1 peak of compound 4 (c).

shorter break-off distance of $2.1 \pm 0.1 \mathrm{~nm}$, consistent with a single molecule length junction. Errors are based on the full width at half height of Gaussian curves fitted to the histogram distribution of break-off distances. Break-off distance histograms for $\mathbf{1}$ are also shown in Figure 2 (bottom panel). Similar to $\mathbf{4}$, the $\pi$-peak is characterized by a "long" break-off distance of $2.8 \pm 0.1 \mathrm{~nm}$. The $\mathbf{A}$ and $\mathbf{B}$ peaks, however, occur at considerably shorter break-off distances of $2.3 \pm 0.1$ and 2.0 $\pm 0.1 \mathrm{~nm}$, respectively, consistent with single molecule junctions. The difference in break-off distances between the $\mathbf{A}$ and $\mathbf{B}$ peaks may arise from different surface binding sites and thiol headgroup(s) sitting in step or defect sites to give a closer Au...Au effective contact spacing for the B group. Such a phenomenon has been noted before and discussed in detail, for both thiol and pyridyl contacting groups. ${ }^{17,30}$ Table 1 summarizes the experimental data and peak assignments.

To test the experimental assignments and to provide further insight into junction configurations involving $\pi$-stacking or direct contact of the phenyl group and a gold contact, theoretical calculations on these systems have been performed using a combination of DFT and nonequilibrium Green's functions formalisms. Figure 3 shows illustrative configurations considered for 1 (Figure $3 a$ ) and 4 (Figure 3b) between gold contacts. In addition to the configuration shown in Figure 3a, we have also considered configurations in which the thiol binds at one contact to a higher coordination "step"-type site (see Supporting Information). Figure $3 \mathrm{~b}$ shows $\mathbf{4}$ binding to the upper contact through a thiol and to the lower contact through a phenyl ring in a face-on configuration to a gold adatom, representative of a high coordination site. We have also considered phenyl group coordination to the surface end-on through the terminal hydrogen (Figure 6, right). Figure 3c shows an optimized aromatic stacking configuration for $\mathbf{4}$.

Table 1 presents a summary of the theoretically computed and the experimentally determined conductance values. Column 6 shows the unadjusted DFT calculations, while the next column along shows computations which have been adjusted using a self-energy and a screening energy correction, following the procedure of Quek et al. ${ }^{45}$ It should be noted that, even in the absence of these corrections, the calculations reproduce the experimentally observed trend for the different conductance peaks, although in some instances the theoretical values are

(45) Quek, S. Y.; Kamenetska, M.; Steigerwald, M. L.; Choi, H. J.; Louie, S. G.; Hybertsen, M. S.; Neaton, J. B.; Venkataraman, L. Nat. Nanotechnol. 2009, 4, 230-234. 


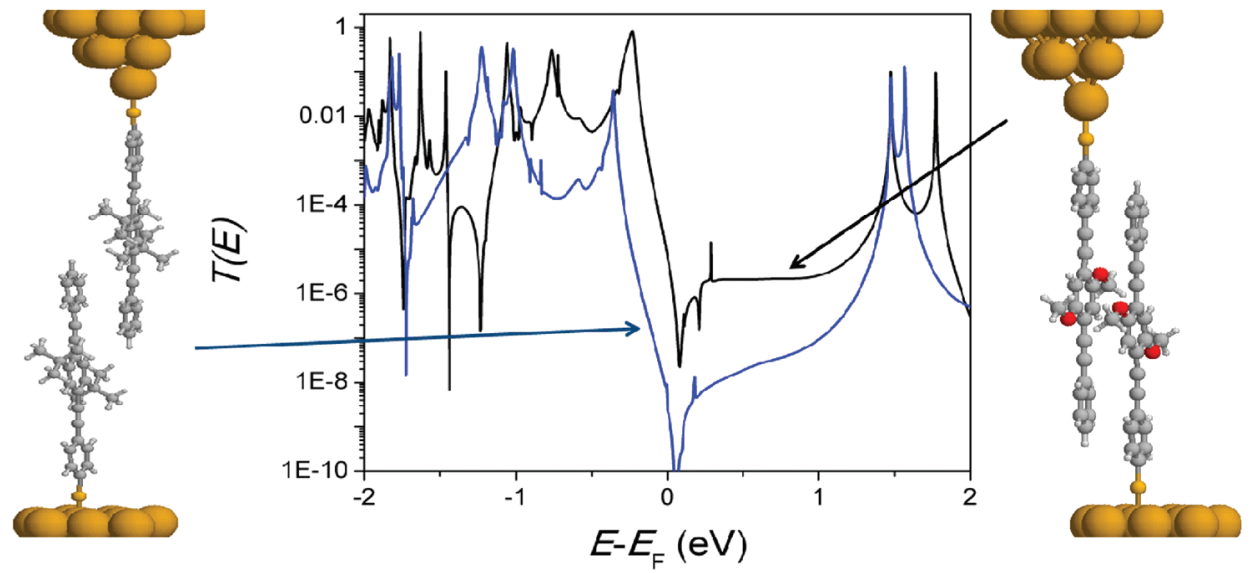

Figure 4. Transport calculations for the $\pi$-stacking configurations of compounds 5 (blue curve and model on left) and $\mathbf{4}$ (black curve and model on right). Notice how the bulky tert-butyl groups impede the stacking of $\mathbf{5}$ (left) and consequently produce a very marked decrease in the transmission at $E=E_{\mathrm{F}}$. On the other hand, there is good stacking overlap for compound 4 (right).
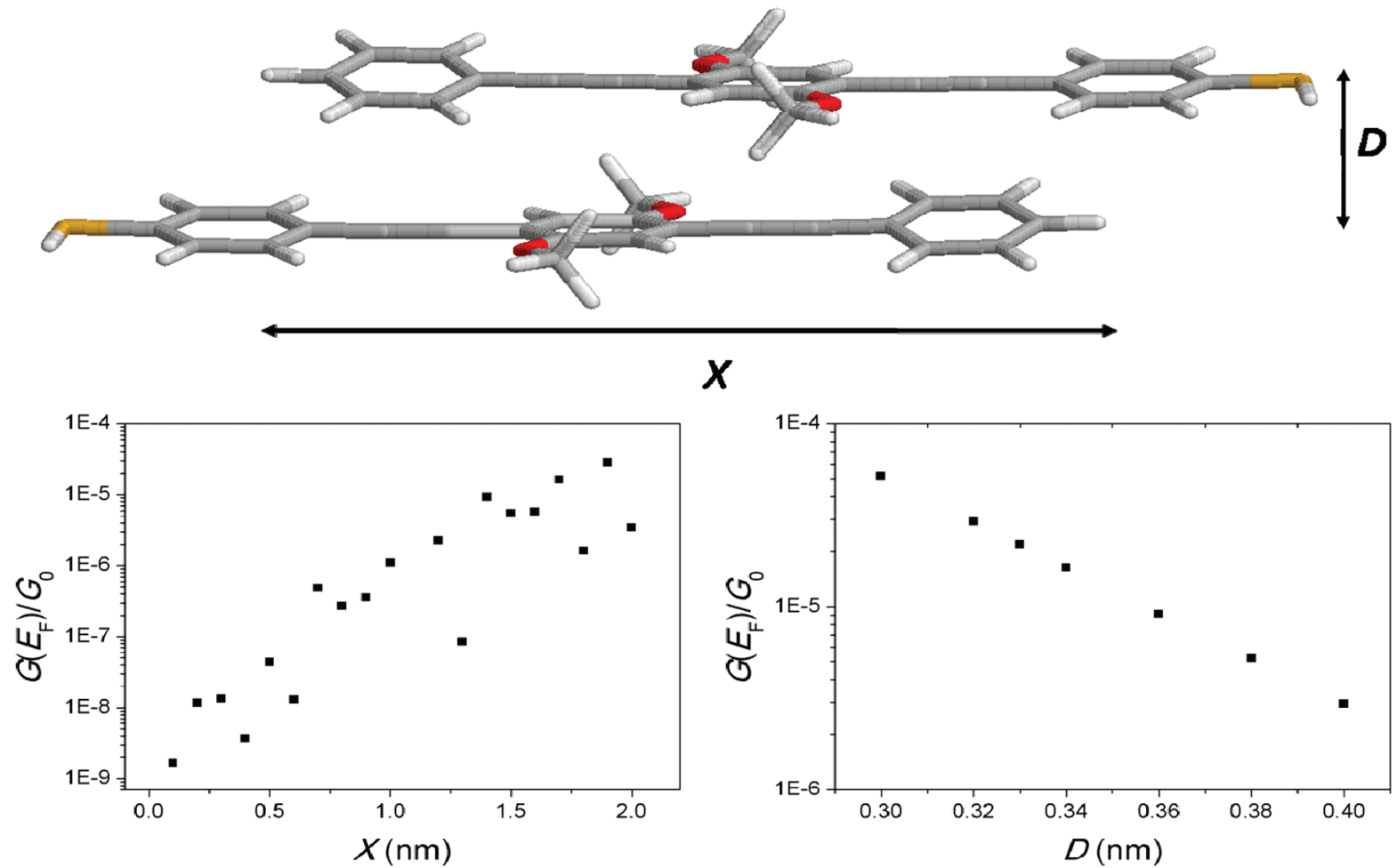

Figure 5. Top: the optimized stacking configuration for 4 . The energy minimized values for $X$ and $D$ are 1.7 and $0.34 \mathrm{~nm}$, respectively. Bottom: variation of the junction conductance as a function of parameter $X$ (left) and $D$ (right).

significantly greater than the experimental values. The "semiempirical" correction ${ }^{40}$ improves the quantitative fit. In the following, we present the $a b$ initio generated transmission curves that give rise to the "unadjusted" conductance values (Table 1 ), and finally mention the corrected conductance for which the quantitative fit is improved.

Figure S7 in the Supporting Information shows transmission curves for 1 binding through the thiol end groups to single gold surface atoms at both contacts. The resonance closest to the Fermi level corresponds to a HOMO feature, indicating that HOMO mediated hole transport is likely to dominate the transport behavior. The ab initio conductance at the Fermi level is $\left(18 \times 10^{-5}\right) G_{0}$ which is $\sim 1$ order of magnitude higher than the experimental value $\left(2 \times 10^{-5}\right) G_{0}$. Figure 4 presents transmission curves for the $\pi$-stacking geometry of $\mathbf{4}$ (black curve) and $\mathbf{5}$ (blue curve). The transmission at the Fermi level is more than 3 orders of magnitude lower for compound $\mathbf{5}$ which has the tert-butyl substituents. Figure 5 shows the optimized (energy minimized) stacking geometries used for $\mathbf{4}$, which is characterized by two parameters; " $X$ " represents the total horizontal distance over which the molecules overlap, while " $D$ " represents their optimum vertical separation. For 4, we find $X$ $=1.7 \mathrm{~nm}$ and $D=0.34 \mathrm{~nm}$. Note that, in the optimized geometry, $\pi$-stacking does not involve face-to-face stacking of the phenyl rings; rather, it involves a staggered configuration of the rings, with the phenyl ring of one molecule facing an acetylene linker in the adjacent molecule. In the case of $\mathbf{5}$ (see Supporting Information), aromatic stacking involves only one phenyl ring and a single acetylene linker on either molecule $(X=0.8 \mathrm{~nm})$ and the two molecules are further apart $(D=$ $0.40 \mathrm{~nm})$. In the X-ray crystal structure of 5, $D=0.39 \mathrm{~nm}$ (Figure S4). The marked differences between the $D$ and $X$ 


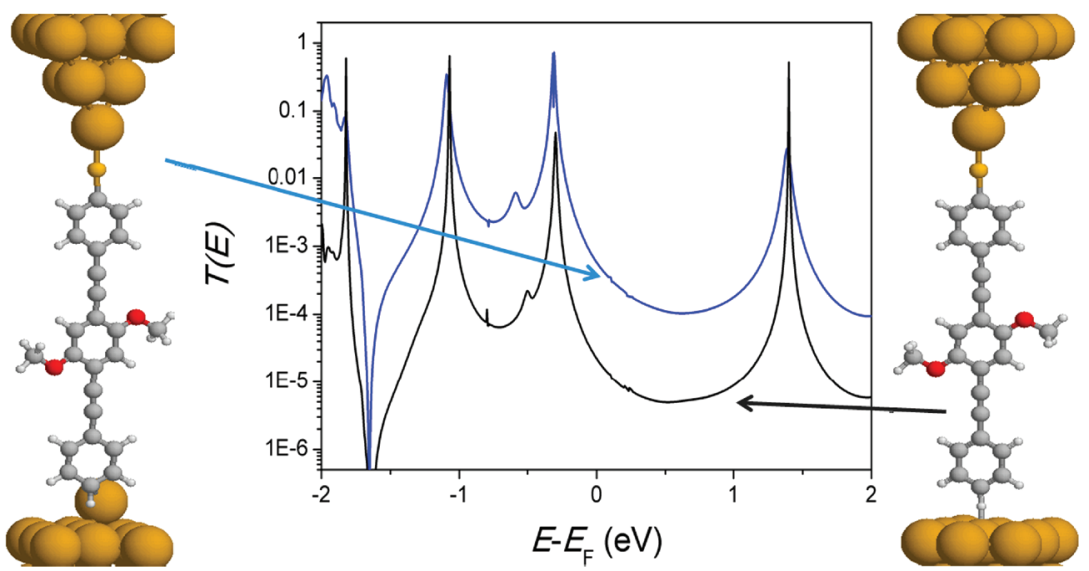

Figure 6. Transport calculations for the proposed "T" configuration of compound $\mathbf{4}$ with the phenyl group coordinating with the lower contact face-on through the end phenyl group to a gold adatom (blue curve and model on left) or end-on to a flat surface (black curve and model on right). Notice how the favored face-on configuration produces a much higher transmission at $E=E_{\mathrm{F}}$. We refer to the face-on contact of the phenyl group to the Au adatom as a "step" position since it is our model for a step or similar defect site on the surface. Other coordination possibilities are considered in the Supporting Information.

parameters for 4 (Figure 5, top) and 5 (see Supporting Information, Figure S6) are the main cause of the large differences in the computed conductance values.

Figure 5 shows how the conductance (i.e., the transmission coefficient $T\left(E_{\mathrm{F}}\right)$ ) of $\mathbf{4}$ varies as the parameters $X$ and $D$ are changed. The conductance decreases monotonically as $D$ is increased (Figure 5, lower right). The conductance also increases as $X$ is increased from 0 to $2 \mathrm{~nm}$ (Figure 5, lower left), although there are peaks and troughs indicating that the theoretically computed junction conductance is very sensitive to variations in $X$ at the sub-angstrom level. Lin et al. ${ }^{46}$ have also theoretically investigated $\pi$-stacked OPE junctions with semi-infinite gold leads. They concluded that the experimental transport characteristics of the $\pi$-stacked OPE junctions ${ }^{18}$ could be accounted for with $D=0.30 \mathrm{~nm},{ }^{46}$ close to our computed value of 0.34 $\mathrm{nm}$ for 4 . However, their preferred geometry involved a cofacial stacking arrangement. ${ }^{46}$ This seems rather unlikely given what is generally known about $\pi$-stacking. ${ }^{47}$

Both our experimental and theoretical data agree with the observation of $\mathrm{Wu}$ et al. ${ }^{18}$ that aromatic coupling is strong enough to allow junction formation and that these junctions are sufficiently electronically transmissive to allow observation in MCBJ or STM configurations. However, our study also shows that there is a competitive formation of differing junction types which can be seen and characterized in the STM based $I(s)$ method, in particular the "T" peak seen for $\mathbf{4}$ and $\mathbf{5}$ which has a short $s_{\text {break-off }}$ (Figure 2) which we thus assign to the end phenyl group contacting with gold to form a molecular bridge which breaks off at the distance consistent with a single molecule length. We have performed DFT computations to further test this experimental assignment. Figure 6 presents transmission curves for $\mathbf{4}$ with the phenyl group in a "step" contact position or with the phenyl $\mathrm{H}$ end-on to the gold contact (see figure for illustration). The former geometry gives a transmission at the Fermi level $>1$ order of magnitude higher than the latter. This demonstrates that phenyl group contacts in high coordination sites can yield highly transmissive systems. These sites are exemplified by the adatom geometry in Figure 6 (left), but

(46) Lin, L. L.; Leng, J. C.; Song, X. N.; Li, Z. L.; Luo, Y.; Wang, C. K. J. Phys. Chem. C 2009, 113, 14474-14477.

(47) Hunter, C. A.; Sanders, J. K. M. J. Am. Chem. Soc. 1990, 112, 55255534. adsorption could instead be at a step edge or to a pyramidal tip; we propose that it is sites of this kind, with face-on interaction of the phenyl ring and a Au contact, which give rise to the $\mathbf{T}$ peak in the high conductance histogram data. The conductance values summarized in Table 1 show both experimentally and theoretically that the $\mathbf{T}$ group is of higher conductance than the $\pi$-stacking configurations. Calculations of adsorption energies for candidate phenyl-gold contact geometries support the likelihood of the step-contact geometry (for the $\mathrm{H}$ end-on to gold configuration we find an adsorption energy value of $0.302 \mathrm{eV}$ for a distance of $2.0 \AA$ above a gold atom). By contrast, for a "step contact" (phenyl ring face-on to the gold adatom contact) a value of $0.86 \mathrm{eV}$ is obtained, where the phenyl ring is $2.4 \AA$ away from the gold adatom. By comparison the gold-thiol adsorption energy is larger with a value of $1.67 \mathrm{eV}$, which is in reasonable agreement with the expected binding strength. ${ }^{48}$ Although there are reported issues concerning the reliability of DFT computations for the adsorption energy of benzene on gold, ${ }^{49}$ the value we estimate for the phenyl-gold adatom adsorption $(0.86 \mathrm{eV})$ is sufficiently high compared to $k T(0.026 \mathrm{eV})$ to merit consideration for our room temperature measurements. We should also add that increasing the microscopic structure of the contact (e.g., a pyramid of $\mathrm{Au}$ atoms rather than the single gold atom in Figure 6, left) may for certain configurations enhance the adsorption "footprint" of the phenyl group and its corresponding adsorption energy. There are other indications in the literature that phenyl groups (benzene) can interact strongly enough with gold to exhibit room temperature surface adsorption, notably the temperature programmed desorption recorded by Nakazawa and Somorjai of benzene on gold. ${ }^{50}$

Conductance values after adjustment using the procedure of Quek et al. ${ }^{45,51}$ are presented in Table 1. This shifts the HOMO resonance further from the Fermi level and reduces the conductances, giving better agreement with the measured values.

(48) Ulman, A. Chem. Rev. 1996, 96, 1533-1554.

(49) Bilic, A.; Reimers, J. R.; Hush, N. S.; Hoft, R. C.; Ford, M. J. J. Chem. Theory Comput. 2006, 2, 1093-1105.

(50) Nakazawa, M.; Somorjai, G. A. Appl. Surf. Sci. 1993, 68, 517-537.

(51) Quek, S. Y.; Venkataraman, L.; Choi, H. J.; Loule, S. G.; Hybertsen, M. S.; Neaton, J. B. Nano Lett. 2007, 7, 3477-3482. 
The slightly poorer agreement for the phenyl contacts is probably due to greater uncertainty in the precise geometry of this contact.

\section{Conclusions}

We have shown that the ability of $\pi$-conjugated molecular wires to form noncovalent aromatically coupled electrical junctions can be controlled through the use of chemical modifications. These chemical modifications can in turn be used to distinguish the nature of the junctions formed and to identify differing conductance peaks in histograms, particularly when used together with measurements of the junction extension at break-off and supporting DFT computations. The use of supramolecular interactions, such as aromatic coupling, is a key long-term goal of molecular electronics. Molecular conductance measurements using STM break junction techniques can help to identify such interactions, although they also identify the diverse range of different junction configurations with widely different conductance values which can occur for any given molecular system.
Acknowledgment. This work was supported by EPSRC under Grants EP/C00678X/1 (Mechanisms of Single Molecule Conductance) and GR/S84064/01 (Controlled Electron Transport Through Single Molecules), QinetiQ and the British Department of Trade and Industry, Royal Society, Northwest Regional Development Agency, the EC FP7 ITN "FUNMOLS" Project No. 212942, and the Royal Thai Government (scholarship to R.J.). S.M. acknowledges his Juan de la Cierva position from the Ministerio de Ciencia e Innovación (Spain). We thank the NWGrid for computing resources.

Supporting Information Available: Synthesis and characterization of compounds 2, 4, and 5; crystal packing and molecular stacks in I and 5; conductance traces recorded by the $I(s)$ technique; details of calculations of optimum stacking geometries for $\mathbf{2}$ and $\mathbf{4}$, influence of contact geometries for $\mathbf{1}$, influence of side groups for $\mathbf{1}$ and $\mathbf{2}$, and a comparison of the uncorrected and corrected transport calculations. This material is available free of charge via the Internet at http://pubs.acs.org.

JA103327F 


\section{Supporting Information \\ Identifying Diversity in Nanoscale Electrical Break Junctions}

Santiago Martin, Iain Grace, Martin R. Bryce, Changsheng Wang, Rukkiat Jitchati, Andrei S. Batsanov, Simon J. Higgins, Colin J. Lambert, Richard J. Nichols

Contents

Section 1. Synthetic procedures

S2-S10

Scheme S1

Synthesis of Compound 4

$\mathrm{S} 2$

Scheme S2

Synthesis of Compounds 2 and 5

S3

Table S1

$X$-ray crystal structures of I and 5

S6

Figure S1

X-ray molecular structures of compounds I (top) and 5

$\mathrm{S} 7$

Figure $\mathrm{S} 2$

Crystal packing of I (top) and 5

Figure S3

Molecular stacks in the structure of I

S9

Figure S4

Molecular stacks in the structure of 5

S10

Section 2.

Conductance Measurements

$\mathrm{S} 11-\mathrm{S} 13$

Figure S5

Typical conductance traces recorded by the $/(s)$ technique

$\mathrm{S} 12$

Section 3. Calculations

S14-S18

Figure S6

Optimum stacking geometry for 4 and 5

$\mathrm{S} 14$

Figure S7

Zero bias transmission coefficient $T(E)$ against energy for four possible

S16

Figure S8 contact geometries of 1

Figure $\mathrm{S} 9$

Comparison of side groups. Zero bias transmission through 1 and 2.

S17

Comparison of uncorrected and corrected $a b$ initio transport calculations

S18

Section 4.

$\pi-1$ and $\pi-2$ peaks

S18

Figure S10

Break-off histograms

S18

Section 5.

References 


\section{Synthetic Procedures}

\section{Synthesis of compound 4}

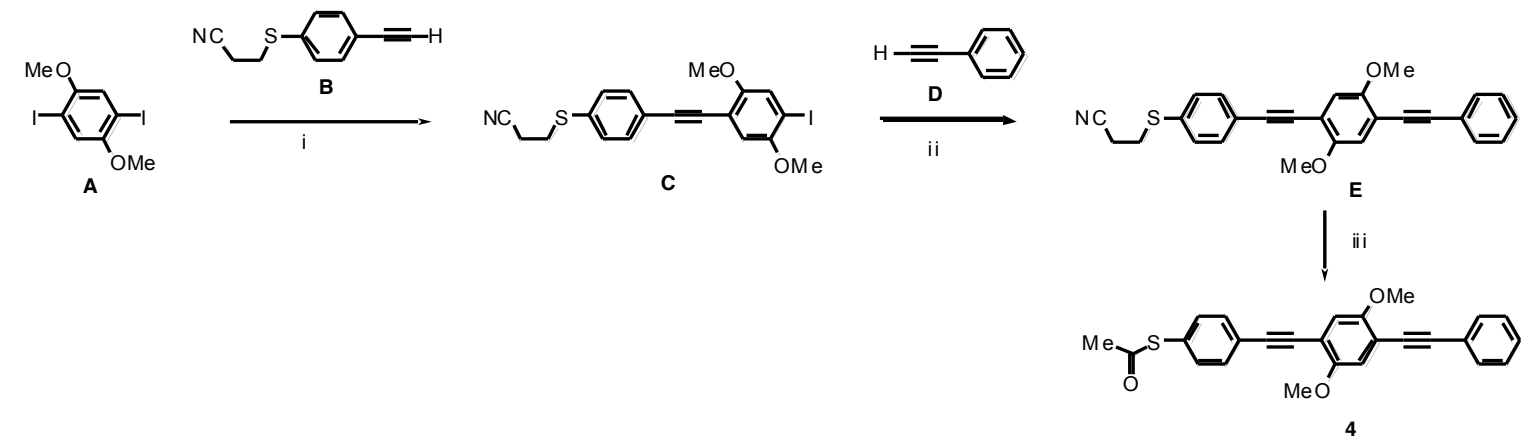

Scheme 1. Reagents and conditions: i, A (1.0 equiv.), B (1.0 equiv.), [Pd( $\left.\left(\mathrm{PPh}_{3}\right)_{4}\right], \mathrm{CuI}, \mathrm{THF}, \mathrm{NEt}_{3}$, $20{ }^{\circ} \mathrm{C}, 38 \%$ yield; ii, C, D (excess), $\left[\mathrm{PdCl}_{2}\left(\mathrm{PPh}_{3}\right)_{2}\right], \mathrm{CuI}, \mathrm{THF}, \mathrm{NEt}_{3}, 60{ }^{\circ} \mathrm{C}, 92 \%$ yield; iii, $\mathrm{CsOH} \cdot \mathrm{H}_{2} \mathrm{O}, \mathrm{DMF}, \mathrm{MeOH}$, then $\mathrm{Ac}_{2} \mathrm{O}, 20{ }^{\circ} \mathrm{C}, 95 \%$ yield.

3-(4-[(4-Iodo-2,5-dimethoxyphenyl)ethynyl]phenylthio) propionitrile C. 1,4-Diiodo-2,5dimethoxybenzene $A(0.585 \mathrm{~g}, 1.5 \mathrm{mmol}), \mathrm{B}^{1}(0.281 \mathrm{~g}, 1.5 \mathrm{mmol})$, [Pd( $\left.\left(\mathrm{PPh}_{3}\right)_{4}\right](40 \mathrm{mg}, 2.5 \mathrm{~mol} \%)$ and $\mathrm{CuI}(6 \mathrm{mg})$ were mixed in THF $(40 \mathrm{~mL})$. The mixture was degassed by bubbling argon for 15 min, followed by the addition of triethylamine $(10 \mathrm{~mL})$. The mixture was stirred at $\mathrm{rt}$ for $12 \mathrm{~h}$ to afford an orange solution. The mixture was dried of solvents under vacuum to afford an orange oil, which was then column chromatographed on silica (DCM eluent) to yield the product as a yellow oil (0.257 g, 38\%). Calcd for $\mathrm{C}_{19} \mathrm{H}_{16} \mathrm{INO}_{2} \mathrm{~S}: \mathrm{C}, 50.79 ; \mathrm{H}, 3.59 ; \mathrm{N}, 3.12$; Found: C, 50.30; H, 3.60; N, 2.90. ${ }^{1} \mathrm{H}-\mathrm{NMR}\left(\mathrm{CDCl}_{3}, 400 \mathrm{MHz}\right): 2.63$ (t, J 7.0 Hz, 2H), 3.17 (t, J 7.0 Hz, 2H), 3.86 (s, 3H), 3.87 (s, 3H), $6.95(\mathrm{~s}, 1 \mathrm{H}), 7.32(\mathrm{~s}, 1 \mathrm{H}), 7.36(\mathrm{~d}, J 8 \mathrm{~Hz}, 2 \mathrm{H}), 7.52(\mathrm{~d}, J 8 \mathrm{~Hz}, 2 \mathrm{H}) .{ }^{13} \mathrm{C} \mathrm{NMR}\left(\mathrm{CDCl}_{3}, 100\right.$ MHz): 25.5, 67.7, 80.9, 114.7, 115.0, 115.7, 116.0, 116.1, 116.2, 129.5, 129.6, 142.36, 142.39, $160.8,163.2$.

3-(4-[(2,5-Dimethoxy-4-(phenylethynyl)phenyl)ethynyl]phenylthio)propionitrile E. Compound C $(0.211 \mathrm{~g}, 0.47 \mathrm{mmol})$ and phenylacetylene $\mathrm{D}(0.25 \mathrm{~mL})$ were dissolved in THF $(5 \mathrm{~mL})$ and triethylamine $(15 \mathrm{~mL})$. $\left[\mathrm{PdCl}_{2}\left(\mathrm{PPh}_{3}\right)_{2}\right](10.5 \mathrm{mg}, 3 \mathrm{~mol} \%)$ and $\mathrm{CuI}(3.2 \mathrm{mg})$ were added and the mixture was stirred at $60{ }^{\circ} \mathrm{C}$ for $1 \mathrm{~h}$ to yield a yellow suspension. TLC indicated that all of C had been consumed. The solvents was removed by vacuum evaporation and the orange solid residue was flash chromatographed on silica (eluent: DCM) to afford a yellow oil which crystallized from DCMethanol to yield $\mathrm{E}$ as yellow plates (184 mg, $92 \%$ ), mp: $112.5-113.6^{\circ} \mathrm{C}$. Calcd for $\mathrm{C}_{27} \mathrm{H}_{21} \mathrm{NO}_{2} \mathrm{~S}$ : C, 
76.57; H, 5.00; N, 3.31. Found: C, 76.49; H, 4.98; N, 3.32. Maldi-Tof MS: $423.2\left(\mathrm{M}^{+}\right) .{ }^{1} \mathrm{H}-\mathrm{NMR}$ $\left(\mathrm{CDCl}_{3}, 400 \mathrm{MHz}\right): 2.60$ (t, J $\left.7.2 \mathrm{~Hz}, 2 \mathrm{H}\right), 3.13$ (t, J $\left.7.2 \mathrm{~Hz}, 2 \mathrm{H}\right), 3.89$ (s, 6H), 7.03 (s, 1H), 7.04 (s, 1H), $7.35(\mathrm{~m}, 5 \mathrm{H}), 7.51-7.59(\mathrm{~m}, 4 \mathrm{H}) .{ }^{13} \mathrm{C} \mathrm{NMR}\left(\mathrm{CDCl}_{3}, 100 \mathrm{MHz}\right): 18.0,29.4,56.28,56.32,85.5$, $86.8,94.1,95.1,112.8,113.5,115.42,115.45,117.7,122.1,123.0,128.2,128.4,130.0,131.5$, $132.3,133.9,153.73,153.77$.

4-([2,5-Dimethoxy-4-(phenylethynyl)phenyl]ethynyl)thiophenol acetate 4. A solution of compound $\mathrm{E}$ (155 mg, $0.366 \mathrm{mmol})$ in DMF $(15 \mathrm{~mL})$ was degassed by bubbling argon for $20 \mathrm{~min}$. $\mathrm{CsOH} \cdot \mathrm{H}_{2} \mathrm{O}$ solution $(100 \mathrm{mg}, 0.6 \mathrm{mmol})$ in methanol $(1 \mathrm{~mL})$ was added and the resultant orange solution was stirred for $2 \mathrm{~min}$. Acetic anhydride $(1 \mathrm{~mL})$ was added and the mixture was stirred for 5 min to yield a pale-yellow solution. Solvents were evaporated and the residual yellow oil was flash columned on silica (eluent DCM) to yield a pale-yellow oil, which crystallized from methanol to afford $\mathrm{F}$ as pale-yellow crystals (143 mg, 95\%), mp: $131.7-133.0{ }^{\circ} \mathrm{C}$. Calcd for $\mathrm{C}_{26} \mathrm{H}_{20} \mathrm{O}_{3} \mathrm{~S}: \mathrm{C}, 75.70$; H, 4.89. Found: C, 75.86; H, 4.89. Maldi-Tof MS: $412.2\left(\mathrm{M}^{+}\right) .{ }^{1} \mathrm{H}-\mathrm{NMR}\left(\mathrm{CDCl}_{3}, 400 \mathrm{MHz}\right): 2.43$ (s, $3 \mathrm{H}), 3.90(\mathrm{~s}, 3 \mathrm{H}), 3.91(\mathrm{~s}, 3 \mathrm{H}), 7.03(\mathrm{~s}, 1 \mathrm{H}), 7.04(\mathrm{~s}, 1 \mathrm{H}), 7.34-7.41(\mathrm{~m}, 5 \mathrm{H}), 7.58(\mathrm{~m}, 4 \mathrm{H}) .{ }^{13} \mathrm{C}$ NMR $\left(\mathrm{CDCl}_{3}, 100 \mathrm{MHz}\right): 30.2,56.5,85.6,87.4,94.2,95.2,113.0,113.8,115.70,115.73,123.2$, $124.5,128.2,128.3,128.4,131.7,132.2,134.1,153.9,154.0$.

Synthesis of Compounds 5 and 2.
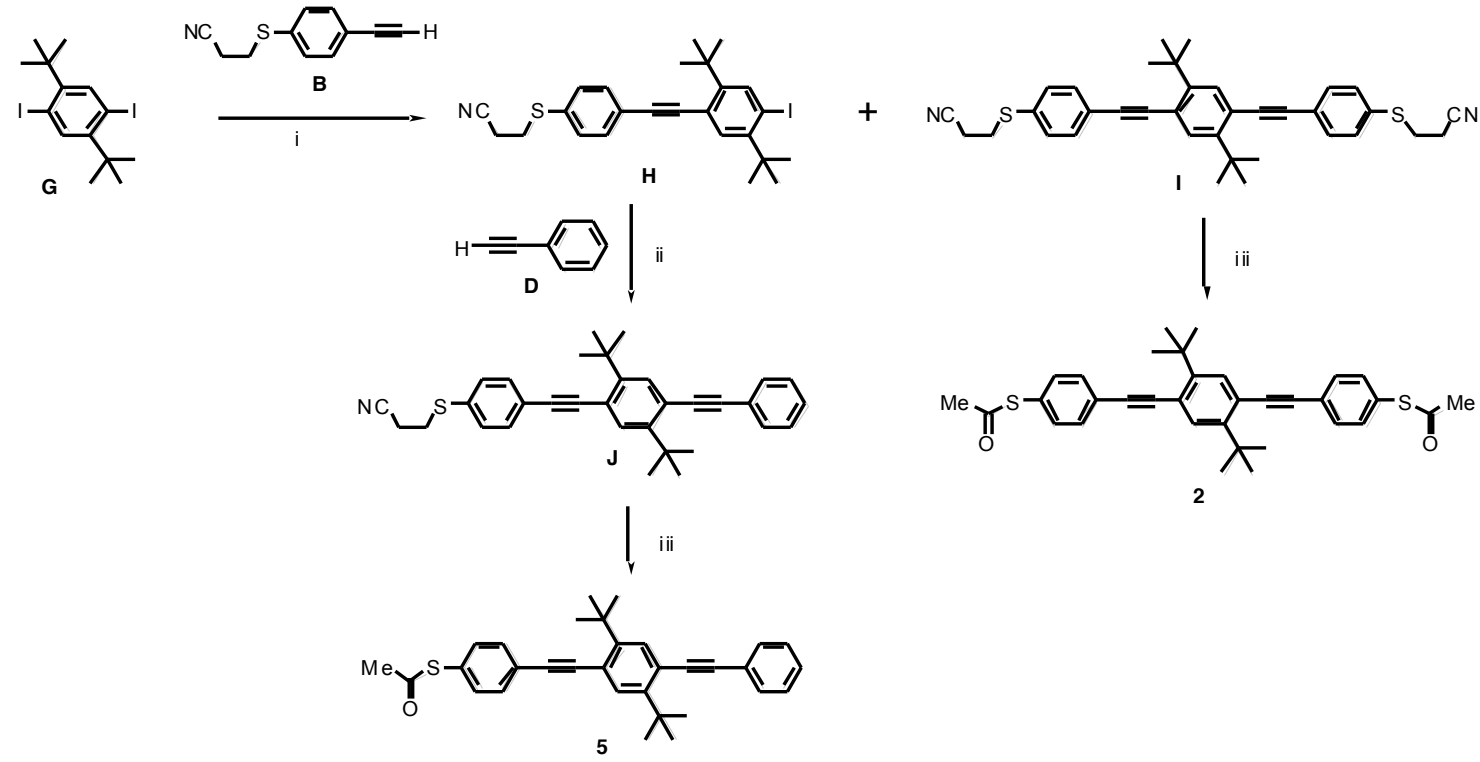
Scheme 2. Reagents and conditions: i, B (1.0 equiv.), G (1.1 equiv.), $\left[\mathrm{PdCl}_{2}\left(\mathrm{PPh}_{3}\right)_{2}\right], \mathrm{CuI}, \mathrm{THF}$, $\mathrm{NEt}_{3}, 50{ }^{\circ} \mathrm{C}, \mathrm{H} 36 \%$ yield; I 16\% yield; ii, $\mathrm{H}, \mathrm{D}$ (2 equiv.), $\left[\mathrm{Pd}\left(\mathrm{PPh}_{3}\right)_{4}\right], \mathrm{CuI}, \mathrm{THF}, \mathrm{NEt}_{3}, 50{ }^{\circ} \mathrm{C}$, $66 \%$ yield; iii, $\mathrm{NaOMe}, \mathrm{THF}$, then $\mathrm{Ac}_{2} \mathrm{O}, 20{ }^{\circ} \mathrm{C}, 597 \%$ yield; $290 \%$ yield.

3-(4-[(4-Iodo-2,5-di-t-butylphenyl)ethynyl]phenylthio)propionitrile $\quad H \quad$ and 1,4-Bis[4-(2cyanoethylsulfanyl)phenylethynyl]-2,6-di-t-butylbenzene I.

Compounds B $(0.50 \mathrm{~g}, 1.1 \mathrm{mmol})$ and $\mathrm{G}$ (which was prepared in $63 \%$ yield from 1,4 -di- $t$ -

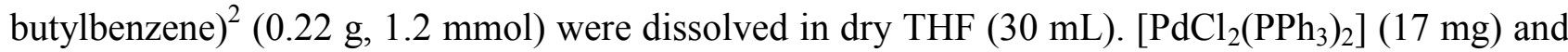
$\mathrm{CuI}(10 \mathrm{mg})$ were added with stirring followed by triethylamine $(30 \mathrm{~mL})$. The mixture was stirred under $\mathrm{Ar}$ at $50{ }^{\circ} \mathrm{C}$ for $4 \mathrm{~h}$. The solution was cooled to room temperature resulting in a yellow suspension. The solids were removed by suction filtration, washed with diethyl ether and the filtrate was vacuum evaporated to remove the solvents. Chromatography of the residue on silica (eluent hexane:ethyl acetate, 4:1 v/v), afford compound $H$ as a white solid (0.20 g, $36 \%$ yield); mp: 97-101 ${ }^{\circ} \mathrm{C},{ }^{1} \mathrm{H}$ NMR (400 MHz, $\left.\mathrm{CDCl}_{3}\right) \delta 1.49$ (s, 9H), 1.51 (s, 9H), 2.61 (t, J $\left.7.3 \mathrm{~Hz}, 2 \mathrm{H}\right), 3.15$ (t, J 7.3 Hz, 2H), $7.36(\mathrm{~d}, J 8.6 \mathrm{~Hz}, 2 \mathrm{H}), 7.47(\mathrm{~d}, J 8.6 \mathrm{~Hz}, 2 \mathrm{H}), 7.51(\mathrm{~s}, 1 \mathrm{H}), 7.95(\mathrm{~s}, 1 \mathrm{H}) .{ }^{13} \mathrm{C} \mathrm{NMR}\left(\mathrm{CDCl}_{3}\right.$, 100.6 MHz): $\delta$ 18.2, 29.8, 29.9, 34.1, 35.1, 36.2, 92.0, 96.5, 117.8, 125.5, 129.9, 130.6, 133.3, 141.2, 147.6, 150.2; MS (MALDI-TOF) $m / z(\%)$ : $501.1\left(\mathrm{M}^{+}, 100\right)$. Next to elute was I as a white solid (0.10 g, 16\% yield); mp: 103-104.5 ${ }^{\circ} \mathrm{C} .{ }^{1} \mathrm{H}$ NMR (400 MHz, $\left.\mathrm{CDCl}_{3}\right) \delta 1.55(\mathrm{~s}, 18 \mathrm{H}), 2.63(\mathrm{t}, J$ $7.3 \mathrm{~Hz}, 4 \mathrm{H}), 3.17$ (t, J $7.3 \mathrm{~Hz}, 4 \mathrm{H}), 7.39$ (d, J $8.3 \mathrm{~Hz}, 4 \mathrm{H}), 7.50$ (d, J $8.3 \mathrm{~Hz}, 4 \mathrm{H}), 7.55(\mathrm{~s}, 2 \mathrm{H}) ;{ }^{13} \mathrm{C}$ NMR $\left(101 \mathrm{MHz}, \mathrm{CDCl}_{3}\right) \delta 18.2,29.7,29.8,29.9,35.4,92.6,95.0,117.7,121.1,130.6,131.8$, 132.4, 148.6; MS (MALDI-TOF) $m / z(\%): 560.3\left(\mathrm{M}^{+}, 100\right)$. From the final fraction $\mathrm{G}(0.20 \mathrm{~g})$ was recovered. Crystals of I for X-ray analysis were grown by slowly evaporating a solution of I in ethyl acetate-hexane mixture.

3-(4-[(2,5-Di-t-butyl-4-(phenylethynyl)phenyl)ethynyl]phenylthio)p ropionitrile J.

Compound $\mathrm{H}(0.29 \mathrm{~g}, 0.57 \mathrm{mmol})$ and phenylacetylene $(0.12 \mathrm{~g}, 1.2 \mathrm{mmol})$ were dissolved in dry THF $(15 \mathrm{~mL}) .\left[\mathrm{Pd}\left(\mathrm{PPh}_{3}\right)_{4}\right](20 \mathrm{mg})$ and $\mathrm{CuI}(6 \mathrm{mg})$ were added with stirring followed by the addition of triethylamine $(15 \mathrm{~mL})$. The mixture was stirred under Ar at $50{ }^{\circ} \mathrm{C}$ for $16 \mathrm{~h}$. The solution was cooled to room temperature resulting in a yellow suspension. The solids were removed by suction filtration, washed with diethyl ether and the filtrate was vacuum evaporated to remove the solvents. Chromatography on silica (eluent DCM-ethyl acetate-hexane 1:5:15 v/v), afforded compound $\mathrm{J}$ as a white solid $(0.18 \mathrm{~g}, 66 \%) ; \mathrm{mp}: 108-110{ }^{\circ} \mathrm{C},{ }^{1} \mathrm{H}$ NMR $\left(400 \mathrm{MHz}, \mathrm{CDCl}_{3}\right) \delta 1.56(\mathrm{~s}$, 9H), 1.57 (s, 9H), $2.63(\mathrm{t}, J 7.3 \mathrm{~Hz}, 1 \mathrm{H}), 3.17(\mathrm{t}, J 7.3 \mathrm{~Hz}, 1 \mathrm{H}), 7.42-7.35(\mathrm{~m}, 5 \mathrm{H}), 7.51$ (d, J 8.5 
$\mathrm{Hz}, 2 \mathrm{H}), 7.59-7.54(\mathrm{~m}, 4 \mathrm{H}) .{ }^{13} \mathrm{C} \mathrm{NMR}\left(101 \mathrm{MHz}, \mathrm{CDCl}_{3}\right) \delta$ 28.6, 28.8, 29.2, 34.3, 90.2, 92.0, 93.9, 94.9, 119.7, 120.5, 122.6, 123.9, 126.9, 127.2, 127.4, 130.0, 130.5, 131.3, 131.4, 133.3, 147.5, 147.6; MS (MALDI-TOF) $m / z(\%): 475.2\left(\mathrm{M}^{+}, 100\right)$.

4-([2,5-Di-t-butyl-4-(phenylethynyl)phenyl]ethynyl)thiophenol acetate 5.

To a degassed solution of compound $\mathrm{J}(0.20 \mathrm{~g}, 0.42 \mathrm{mmol})$ in dry THF $(30 \mathrm{~mL})$ was added sodium methoxide solution ( $25 \%$ in methanol, $0.5 \mathrm{~mL}$ ). The mixture was stirred at room temperature under argon for $20 \mathrm{~min}$ to afford a thick yellow suspension. Acetic anhydride $(1.0 \mathrm{~mL})$ was added and the mixture was stirred for $0.5 \mathrm{~h}$ to afford a pale-yellow solution. Solvents were removed by vacuum evaporation, followed by the addition of dichloromethane $(50 \mathrm{~mL})$ to the solid residue. The mixture was sonicated for $2 \mathrm{~min}$ then suction filtered through a Celite pad. The filtrate was concentrated and chromatographed on silica (eluent hexane:ethyl acetate $4: 1 \mathrm{v} / \mathrm{v})$ to give 5 as a white solid $(0.19 \mathrm{~g}$, 97\%), mp: $109.5-11{ }^{\circ} \mathrm{C} .{ }^{1} \mathrm{H}$ NMR (400 MHz, $\left.\mathrm{CDCl}_{3}\right) \delta 1.57$ (s, 9H), $1.58(\mathrm{~s}, 9 \mathrm{H}), 2.45$ (s, 3H), 7.39 - $7.36(\mathrm{~m}, 3 \mathrm{H}), 7.43(\mathrm{~d}, J 8.5 \mathrm{~Hz}, 2 \mathrm{H}), 7.61-7.54(\mathrm{~m}, 6 \mathrm{H}) .{ }^{13} \mathrm{C} \mathrm{NMR}\left(101 \mathrm{MHz}, \mathrm{CDCl}_{3}\right) \delta 28.6$, 28.8, 28.9, 29.2, 34.3, 90.2, 92.0, 93.9, 94.9, 119.7, 120.5, 122.6, 123.9, 126.9, 127.2, 127.4, 130.0, 130.5, 131.3, 131.4, 133.3, 147.5, 147.6, 192.5. MS (MALDI-TOF) $m / z(\%) 464.3\left(\mathrm{M}^{+}, 100\right)$. Calcd for $\mathrm{C}_{32} \mathrm{H}_{32} \mathrm{OS}$ : C, 82.71; H, 6.94. Found: C, 82.55; H, 6.80. Crystals for X-ray analysis were grown by slowly evaporating a solution of 5 in ethyl acetate-hexane mixture.

\section{1,4-Bis[4-(acetylsulfanyl)phenylethynyl]-2,6-di-t-butylbenzene 2.}

Following the procedure for 5 , compound I $(0.36 \mathrm{~g}, 0.64 \mathrm{mmol})$ in dry THF $(30 \mathrm{~mL})$ and sodium methoxide solution $(25 \%$ in methanol, $0.5 \mathrm{~mL})$ followed by acetic anhydride $(2.0 \mathrm{~mL})$ gave a crude product which was chromatographed on silica (eluent hexane:ethyl acetate 4:1 v/v) to give 2 as a white solid (0.31 g, 90\%), mp: 130-132 ${ }^{\circ} \mathrm{C} .{ }^{1} \mathrm{H}$ NMR (400 MHz, $\left.\mathrm{CDCl}_{3}\right): \delta 1.54$ (s, 18H), $2.43(\mathrm{~s}$, $6 \mathrm{H}), 7.40(\mathrm{~d}, J 8.0 \mathrm{~Hz}, 4 \mathrm{H}), 7.55(\mathrm{~s}, 2 \mathrm{H}), 7.56(\mathrm{~d}, J 8.0 \mathrm{~Hz}, 4 \mathrm{H}) .{ }^{13} \mathrm{C} \mathrm{NMR}\left(101 \mathrm{MHz}, \mathrm{CDCl}_{3}\right) \delta$ 29.9, 30.3, 35.4, 93.0, 95.1, 121.1, 124.9, 128.0, 131.6, 132.4, 134.3, 148.7, 193.5. MS (MALDITOF) $m / z(\%) 538.2\left(\mathrm{M}^{+}, 100\right)$. Calcd for $\mathrm{C}_{34} \mathrm{H}_{34} \mathrm{O}_{2} \mathrm{~S}_{2}$ : C, 75.80; H, 6.36. Found: C, 76.00; H, 6.41. 
$X$-ray crystal structures of I and 5

Table S1. Crystal data

\begin{tabular}{lll}
\hline Compound & $\mathbf{I}$ & $\mathbf{5}$ \\
\hline CCDC dep. no. & 759149 & 759150 \\
Formula & $\mathrm{C}_{36} \mathrm{H}_{36} \mathrm{~N}_{2} \mathrm{~S}_{2}$ & $\mathrm{C}_{32} \mathrm{H}_{32} \mathrm{OS}$ \\
$\mathrm{M}$ & 560.79 & 464.64 \\
$\mathrm{~T}, \mathrm{~K}$ & 120 & 120 \\
Crystal system & triclinic & triclinic \\
Space group (no.) & $\mathrm{P} \overline{1}(\# 2)$ & $\mathrm{P} \overline{1}(\# 2)$ \\
$a, \AA$ & $6.6930(14)$ & $6.1691(6)$ \\
$b, \AA$ & $13.459(3)$ & $11.0563(10)$ \\
$c, \AA$ & $16.804(3)$ & $19.9938(18)$ \\
$\alpha,{ }^{\circ}$ & $95.46(3)$ & $95.555(9)$ \\
$\beta,^{\circ}$ & $92.07(3)$ & $97.928(8)$ \\
$\gamma,{ }^{\circ}$ & $98.41(3)$ & $104.921(8)$ \\
$U, \AA^{3}$ & $1488.8(5)$ & $1292.6(2)$ \\
$Z$ & 2 & 2 \\
$D_{\mathrm{x}}, \mathrm{g} \mathrm{cm}^{-3}$ & 1.251 & 1.194 \\
$\mu, \mathrm{mm}^{-1}$ & 0.21 & 0.15 \\
$\mathrm{Refls} \mathrm{collected}$ & 10284 & 13974 \\
$\mathrm{Unique}^{\circ}$ & $5207,2482^{a}$ & $5900,4542^{a}$ \\
$R_{\text {int }}$ & 0.109 & 0.032 \\
$R(F)^{a}$ & 0.080 & 0.044 \\
$\mathrm{w} R\left(F^{2}\right)$ & 0.186 & 0.112 \\
\hline${ }^{\circ}$ & & \\
\hline & &
\end{tabular}

${ }^{a}$ Reflections with $\triangleright 2 \sigma(/)$

Single-crystal diffraction experiments were carried out on a Siemens 3-circle SMART 1000 CCD detector diffractometers, using graphite-monochromated Mo- $K_{\alpha}$ radiation $(\lambda=0.71073 \AA)$ and Cryostream (Oxford Cryosystems) open-flow $\mathrm{N}_{2}$ cryostats. The structures were solved by direct methods and refined by full-matrix least squares against $F^{2}$ of all data, using SHELXTL software. ${ }^{3}$ 
All non-hydrogen atoms were refined in anisotropic approximation, methyl groups as rigid rotating bodies and other $\mathrm{H}$ atoms using riding model. Crystal data and other experimental details are listed in Table 1, full structural information has been deposited with Cambridge Crystallographic Data Centre.
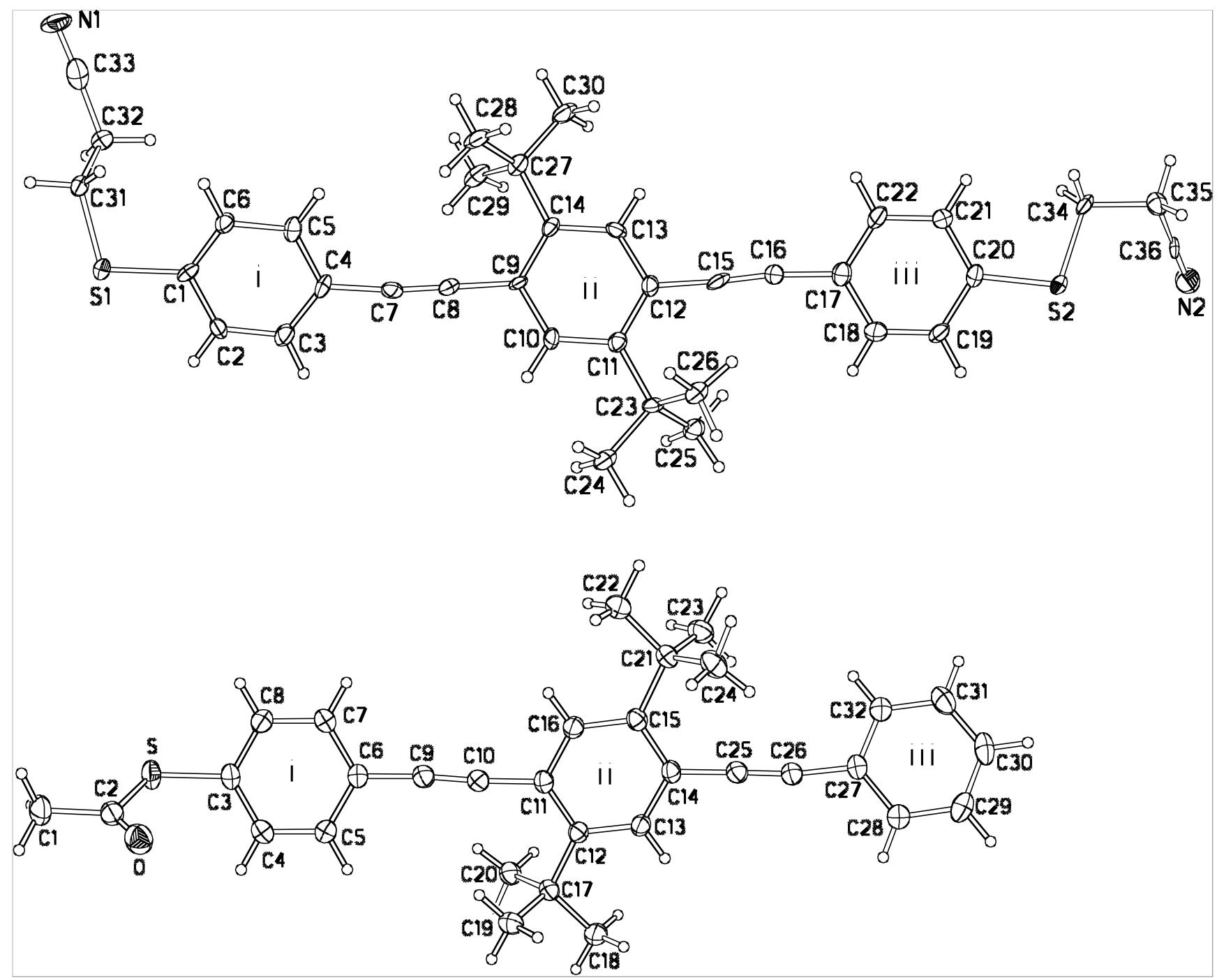

Figure S1. X-ray molecular structures of compounds I (top) and 5. Thermal ellipsoids are shown at the $50 \%$ probability level.

Molecular structures are shown in Figure S1. The intramolecular dihedral angles between arene rings in $\mathrm{I}$ are $\mathrm{i} / \mathrm{ii} 20.2^{\circ}$, i/iii $19.2^{\circ}$ and ii/iii $39.2^{\circ}$, in $5 \mathrm{i} /$ ii $19.5^{\circ}$, i/iii $12.4^{\circ}$ and ii/iii $31.8^{\circ}$, i.e. much smaller than in bis-methoxy analogues, where the angles between the central and terminal rings varied from $49^{\circ}$ to $82^{\circ}$. The intramolecular sulfur-sulfur distance in I equals $20.0 \AA \AA$. In molecule 5 the corresponding interplanar angles are similar. The thioacyl group in 5 is inclined to the arene 
plane (i) by $60.8^{\circ}$. Both structures are triclinic with one molecule per asymmetric unit, hence all molecules within each structure are parallel (Fig. S2).
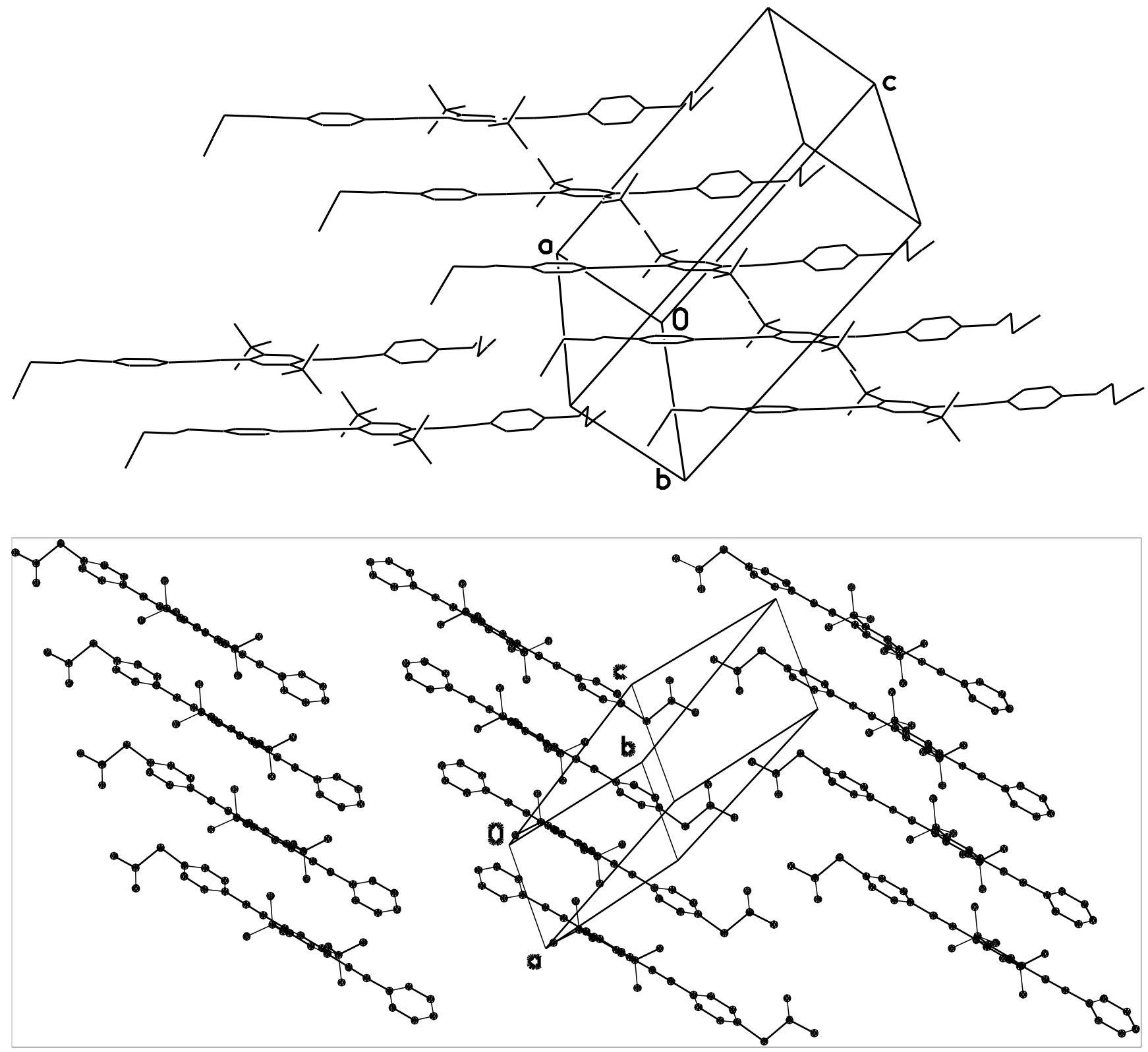

Figure S2. Crystal packing of I (top) and 5 (H atoms are omitted). 

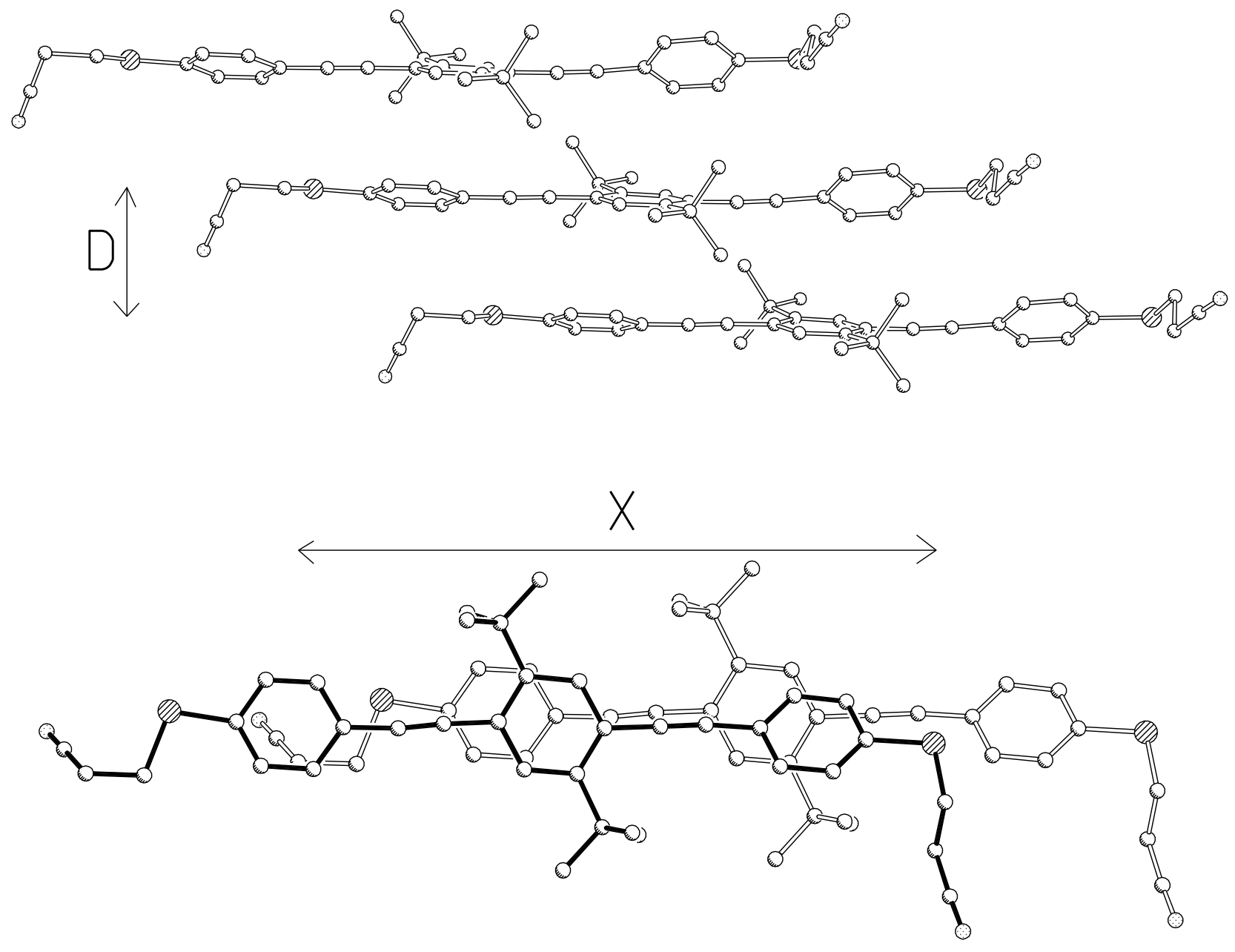

Figure S3. Molecular stacks in the structure of I (two orthogonal projections). $\mathrm{D}=0.38 \mathrm{~nm}, \mathrm{X}=1.7$ $\mathrm{nm}$. 

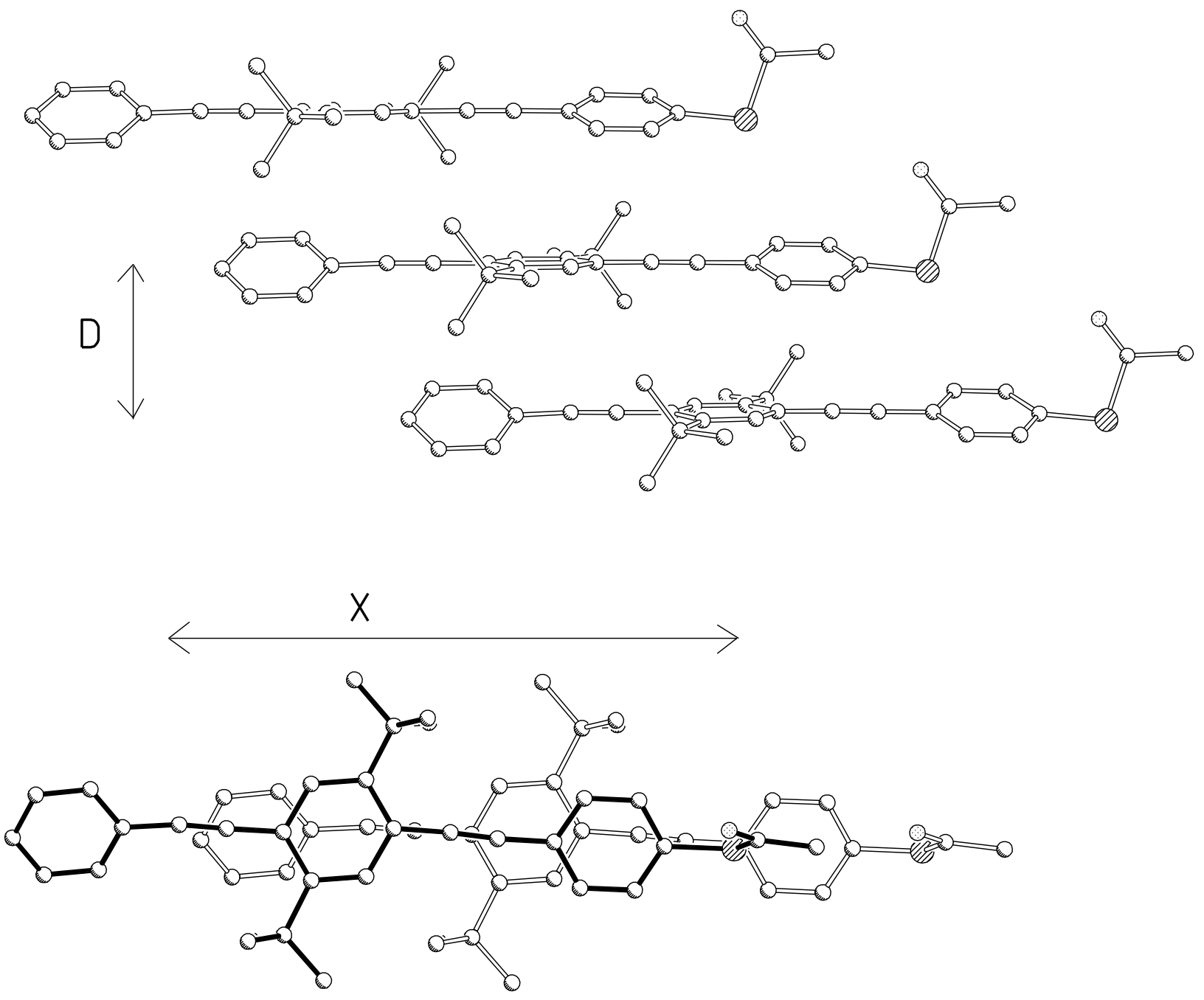

Figure S4. Molecular stacks in the structure of 5 (two orthogonal projections). $D=0.39 \mathrm{~nm}, \mathrm{X}=1.45$ nm.

The basic packing motif in both structures is stacks (slanted in the longitudinal direction) of molecules related via the $a$ translation. Within a stack, the mean separation (D) between molecular 'rods' (see Figs. S3 and S4) is ca. $3.8 \AA$ in I and $3.9 \AA$ in 5, although some intermolecular (atomatom) contacts are much shorter, e.g. $\mathrm{C}(3) \ldots \mathrm{C}\left(9^{\prime}\right) 3.49 \AA$ and $\mathrm{C}(3) \ldots \mathrm{C}\left(10^{\prime}\right) 3.46 \AA$ in I or $\mathrm{C}(14) \ldots \mathrm{C}(28) 3.52 \AA$ and $\mathrm{C}(7) \ldots \mathrm{C}(16) 3.60 \AA$ in 5 . The approximately linear part of molecule I has the overall length of ca. $22 \AA$ [from $\mathrm{S}(1)$ to $\mathrm{C}(35)$ ], that of molecule 5 is ca. $19 \AA$ long [from $\mathrm{S}$ to $\mathrm{H}(30)]$. Of these, the section overlapping with each adjacent molecule has the length $\mathrm{X}=17 \AA$ in I and $14.5 \AA$ in 5 . 


\section{Conductance Measurements.}

An STM was deployed for the single molecule electrical measurements, by using the "/(s) method" (where $/=$ current and $s=$ distance), as described in detail previously. ${ }^{1,4-6}$ In brief, the $/(s)$ method involves the repeated formation and cleavage of molecular bridges generally formed between a gold STM tip and a Au substrate). Representative /(s) curves are shown in Figure S5 for the four OPE derivatives employed in this study. During an $/(s)$ scan the tip is retracted and the electrical conductance of the molecular target is recorded as the molecule is fully extended in the gap between STM-tip and substrate. Figure S5 exhibits the characteristic current steps which are seen in the retraction process as the Au|molecule(s) $\mid$ Au electrical junctions are cleaved. ${ }^{5}$ Many $/(s)$ scans are recorded and they are statistically analyzed in conductance histogram plots which include all the current (junction conductance) data in the $/(\boldsymbol{s})$ scans. In this work we have initiated $/(S)$ retraction scans with a scan rate of $25 \mathrm{~nm} \mathrm{~s}^{-1}$ from the position defined by the set-point values of tunneling current $\left(I_{0}\right)$ and tunneling voltage $\left(U_{0}\right)$ to a distance of $+2.5 \mathrm{~nm}$. We have recorded data using both low and high current pre-amplifiers since the histogram peaks span a relative wide conductance range to optimize observation (Figure S5). The low and high current preamplifiers were calibrated using resistors, while the voltage to length conversion factor of the STM was calibrated using images of $\mathrm{Au}(111)$ mono-atomic steps (0.235 nm height). 

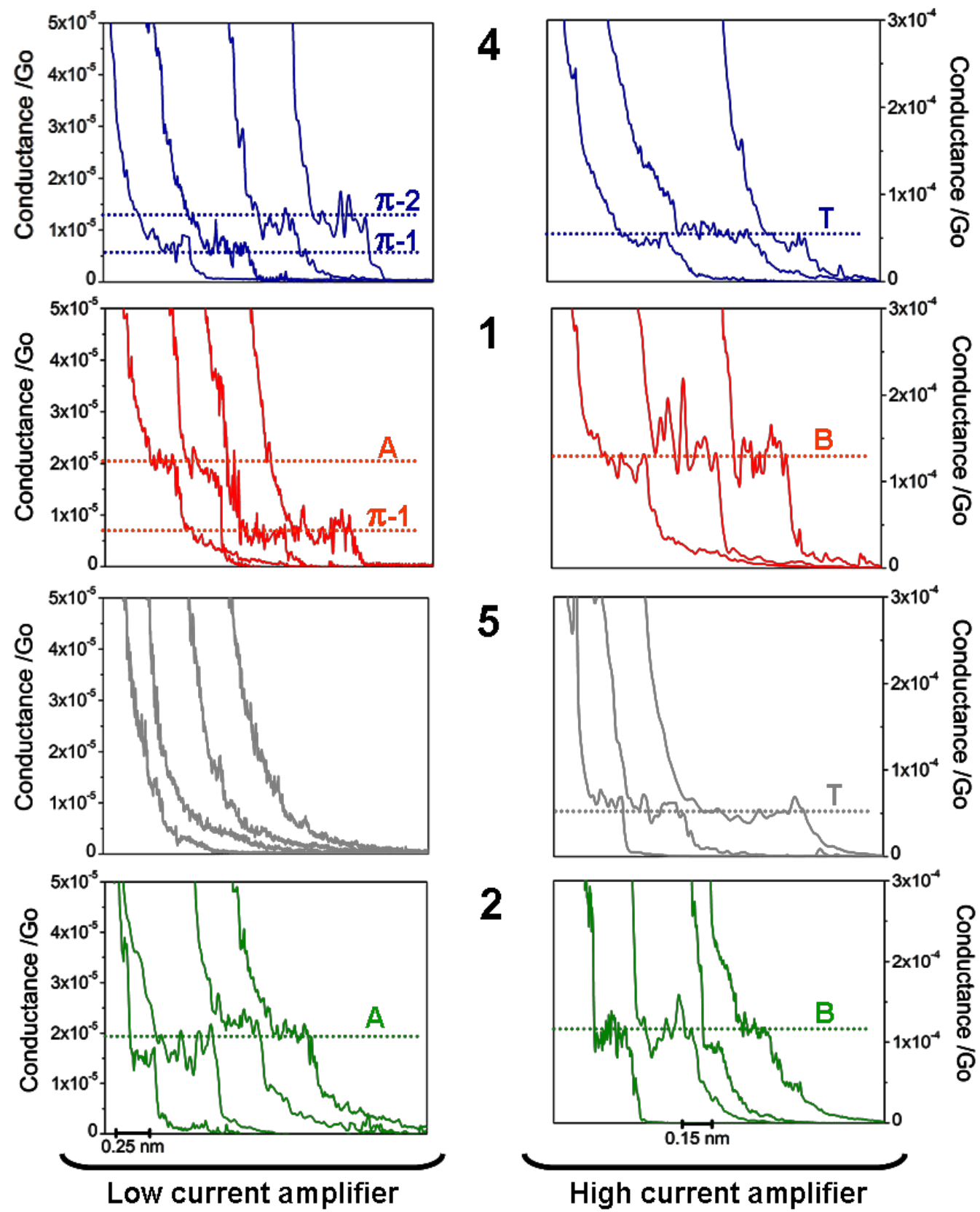

Figure S5. Typical conductance traces recorded by the $/(s)$ technique using either a low current amplifier and low set-point current value, $I_{0}=5 \mathrm{nA}$ and $U_{t}=0.6 \mathrm{~V}$ (left panel) or a high current amplifier and high set-point current value, $I_{0}=60 \mathrm{nA}$ and $U_{t}=0.6 \mathrm{~V}$ (right panel) for the compounds $(4,1,5,2)$ used in this work. Curves are shifted horizontally for clarity and conductance data are presented in units of the conductance quantum $G_{0}=2 e^{2} / h=77.4 \mu \mathrm{S}$. $\mathrm{U}_{t i p}=0.6 \mathrm{~V}$. 
Determination of $s_{\text {break-off }}$ histograms

The first step in the determination of the break-off distance is the calibration of the z-piezo elongation factor. This is obtained by measuring the height of monatomic steps on $\mathrm{Au}(111)$ (0.235 $\mathrm{nm}$ ) and then accordingly adjusting the scanner calibration file to match this value. The next step is to determine the relationship between the set-point current $\left(/_{0}\right)$ and the STM tip to sample separation for a given bias voltage of relevance to the conductance measurements. A number of $/(S)$ scans are recorded during the measurement process and those are selected which show an exponential decrease of the tunneling current as the tip is retracted from the surface. These scans showing a monotonic exponential decrease are characteristic of circumstances in which a molecular bridge is not formed between the STM tip and gold substrate. The exponential decay curves are then plotted as $\ln (/)$ versus $s$ in the distance range of relevance to the $/(S)$ experiment. Slopes of these plots are then obtained; these fall typically in the range of $(5.07 \pm 1.30)$ to $(6.13 \pm 1.08) \mathrm{nm}^{-1}$ for the measurements conducted here. This gives the relationship between $\ln (/)$ versus $S$, but it does not give the initial distance $\left(s_{0}\right)$ between gold tip and sample at the beginning of the retraction scan. To obtain an estimate of this distance, the $\ln (/$ ) versus $s$ plots are extrapolated back to the current which corresponds to the metal-to-metal point contact conductance $(77.4 \mu \mathrm{S})$. The following formula is then used to estimate the distance between tip and surface $\left(s_{0}\right)$ at the beginning of an $/(s)$ retraction scan when the tunneling current is set to $l_{0}:{ }^{1,4,7}$

$$
s_{0}=\frac{\ln \left(G_{0} \times U_{t} / I_{0}\right)}{d \ln (/) / d s}
$$

To obtain the absolute distance between STM tip and gold substrate, this $\boldsymbol{S}_{0}$ value is then added to the experimentally determined parameter $\boldsymbol{S}_{\mathrm{w}}$, which is the measured distance at the end of the current plateau before the molecular junction breaks in the $/(S)$ scan. This then gives the break-off distance $\left(s_{\text {break-off }}=s_{0}+s_{\mathrm{w}}\right)$. These experimentally determined break-off distances from many $/(s)$ retraction experiments are displayed in a histogram representation ("break-off distance histograms"). The equation shown above for calibration of distance is based on a simple tunneling model and does not include quantification of the deformability of the gold probe itself during the stretching process. Such corrections are not included, but may in the future be possible using conductive AFM probes and simultaneous measurements of conductance and force. $\mathrm{Xu}$ et $\mathrm{al}^{8}{ }^{8}$ have demonstrated electromechanical measurements on STM-BJs, while Morita et al. ${ }^{9}$ have demonstrated the use of mechanical (Hertzian) models to estimate deformation of molecular monolayers (during compression by an AFM tip). 


\section{Calculations}

\section{Stacking geometry}

In the first step of the theoretical calculations of the conductance the optimum geometry of each of the molecular wires is found. This is achieved by using the SIESTA density-functional-theory code. ${ }^{10}$ The molecules are relaxed until the force component is less than $0.01 \mathrm{eV} / \AA$. We used a double- $\zeta$ basis set, an energy cut-off of 150 Ry to define the real space grid and the exchange correlation is described by the local density approximation. ${ }^{11}$ (For consistency we use these parameters in both the energy and transport calculations.)

For the case where a stacked geometry of two molecules is formed between the leads, the optimum geometry was obtained by calculating the ground state energy for a number of differing configurations which are defined by the overlap length $\mathrm{X}$ and the molecular separation $\mathrm{D}$ (see Fig. S6). The overlap X was varied between $0 \AA$ (when only the end groups of each molecule overlap) and the length of the molecule (20 $\AA$ ) and the separation D was varied between 2.5 and $4.5 \AA$. The ground state energy for a total of 600 different geometries was calculated and the optimum arrangement found using this approach is shown in Figure S6. The overlap length $X$ is found to be $1.7 \mathrm{~nm}$ and the separation $\mathrm{D}$ is $0.34 \mathrm{~nm}$, so the phenyl rings are slightly displaced from one another. This process was repeated for 1, 2 and 5. Similar stacking geometries were found for 1 and 4, because they only differ by end groups. In the case of molecules 2 and 5 the optimum overlap length $\mathrm{X}$ is $0.8 \mathrm{~nm}$, which is much shorter than that of 1 and 4 and the optimum separation $\mathrm{D}$ is $0.4 \mathrm{~nm}$, which is larger than that of 1 and 4, due to the presence of bulky t-butyl groups, which force the molecules apart. Figure S6 shows the stacking geometries for the monothiol molecules 4 (-OMe side groups) and 5 (-t-Bu side groups), with $D=0.34 \mathrm{~nm}$ in the former case and $0.4 \mathrm{~nm}$ in the later case.

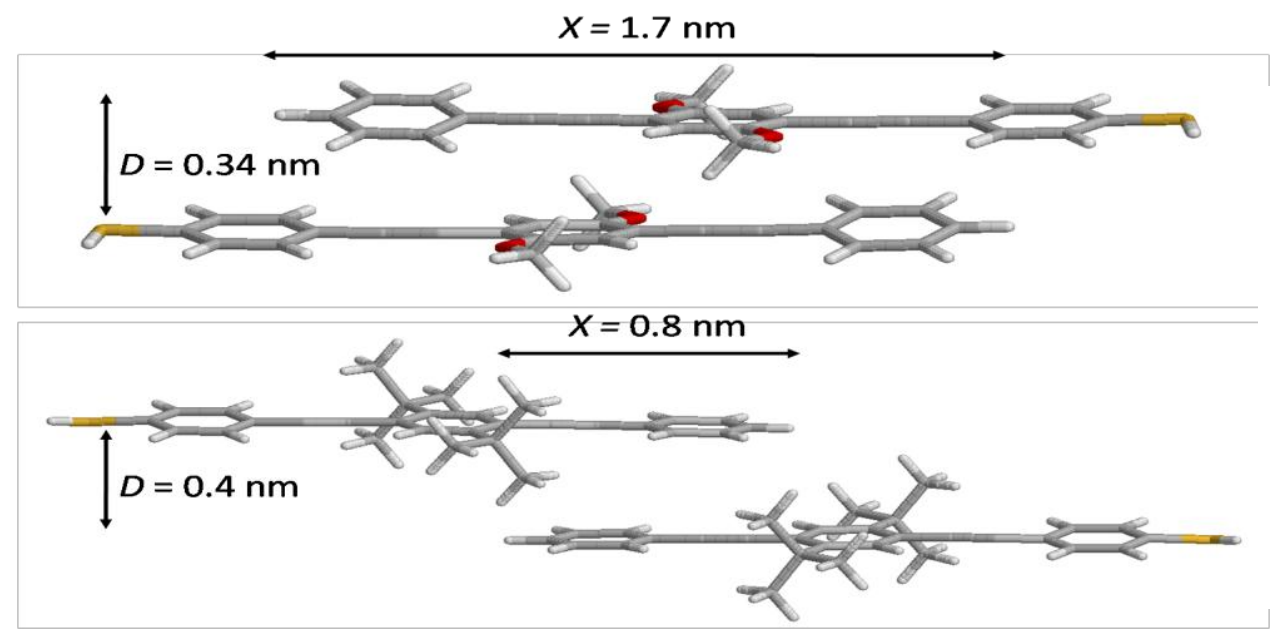

Figure S6. Optimum stacking geometry for 4 (top) and 5 (bottom) 


\section{Conductance calculations}

The next step was to calculate the conductance through each of these molecular wires, for both the individual and stacked arrangements. To do this the molecules were extended to include the gold leads. To model the geometry of the experimental STM junction one lead was given a flat surface, while the second lead geometry was terminated with a 'pyramid' of gold atoms to model the STM tip (Figure S7a). For this series of molecules there are many possible ways the molecules can bind to the electrodes. In the case of dithiol molecules, the optimum binding distance between the sulfur atom and gold tip atom was computed to be $2.4 \AA$ and a corresponding binding energy of $1.6 \mathrm{eV}$ was found (taking into account a BSSE correction due to the localized basis set used in SIESTA); this is in reasonable agreement with previous work. ${ }^{12} \mathrm{We}$ also assume that the binding at the flat surface is to an 'atop' atom with an equivalent binding distance.

Gold leads were constructed from layers of (111) gold with 9 atoms in each layer. In the extended molecule each lead contained 6 layers of gold to ensure that charge transfer effects at the molecule lead interface are included; this was sufficient to ensure that the transmission curves converged. For the STM tip contact a "pyramid" of 4 gold atoms was added to one surface and for the "step calculation" a single ad-atom was placed on-top of the flat surface. The phrase "step calculation" refers to these gold ad-atom sites, which provide high coordination sites for the contact between molecule and surface; the term "step" is used to signify that this is a basic representation of a surface "step" or high coordination site. The zero bias conductance is then calculated using the $a b$ initio transport code SMEAGOL. ${ }^{13}$

\section{Contact dependence}

Figure S7 shows transport calculation for 1 with a variety of different gold contact configurations. In Figure S7a the top contact features a pyramidal tip with sulfur contacting the end-most gold atom, while the bottom contact is a flat gold surface. In Figure S7b a gold ad-atom has been included on the bottom contact, with sulfur adsorbing in the resulting high-coordination ("step") site. Figure S7c on the other hand features 2 "flat" contacts. Finally, Figure S7d employs a flat bottom contact and a pyramidal gold tip; however, the sulfur is displaced upwards into a high coordination site of the gold pyramid (compare Figure S7a and S7d). For a single molecule of 1 contacted between tip and lead, the calculated distance between the gold atoms of the respective contacts is approximately $2.5 \mathrm{~nm}$ which is similar to the experimental break-off distance of $2.26 \mathrm{~nm}$. The zero bias transmission for this structure can be seen in Figure S7a and the conductance is given by the value of the T(E) at the Fermi energy $(0 \mathrm{eV})$. Here $G=\left(18 \times 10^{-5}\right) G_{0}$ which is about ten times larger than the experimental 
value. This can be compared with the system where both lead surfaces are flat (Figure S7c), which has a significantly increased conductance value of approximately $\left(430 \times 10^{-5}\right) G_{0}$. This difference is due to the asymmetry in the coupling for the tip model; the coupling strength at the tip is weaker than the flat surface and thus reduces the conductance. The asymmetry of the contacts can be seen in the LUMO resonance of Figure S7a which does not have a magnitude of $1 G_{0}$ in comparison to the symmetrical case in Figure S7c. The weaker coupling also reduces the width of this resonance. This behaviour is expected from the typical Breit-Wigner description of resonant transport through molecule.
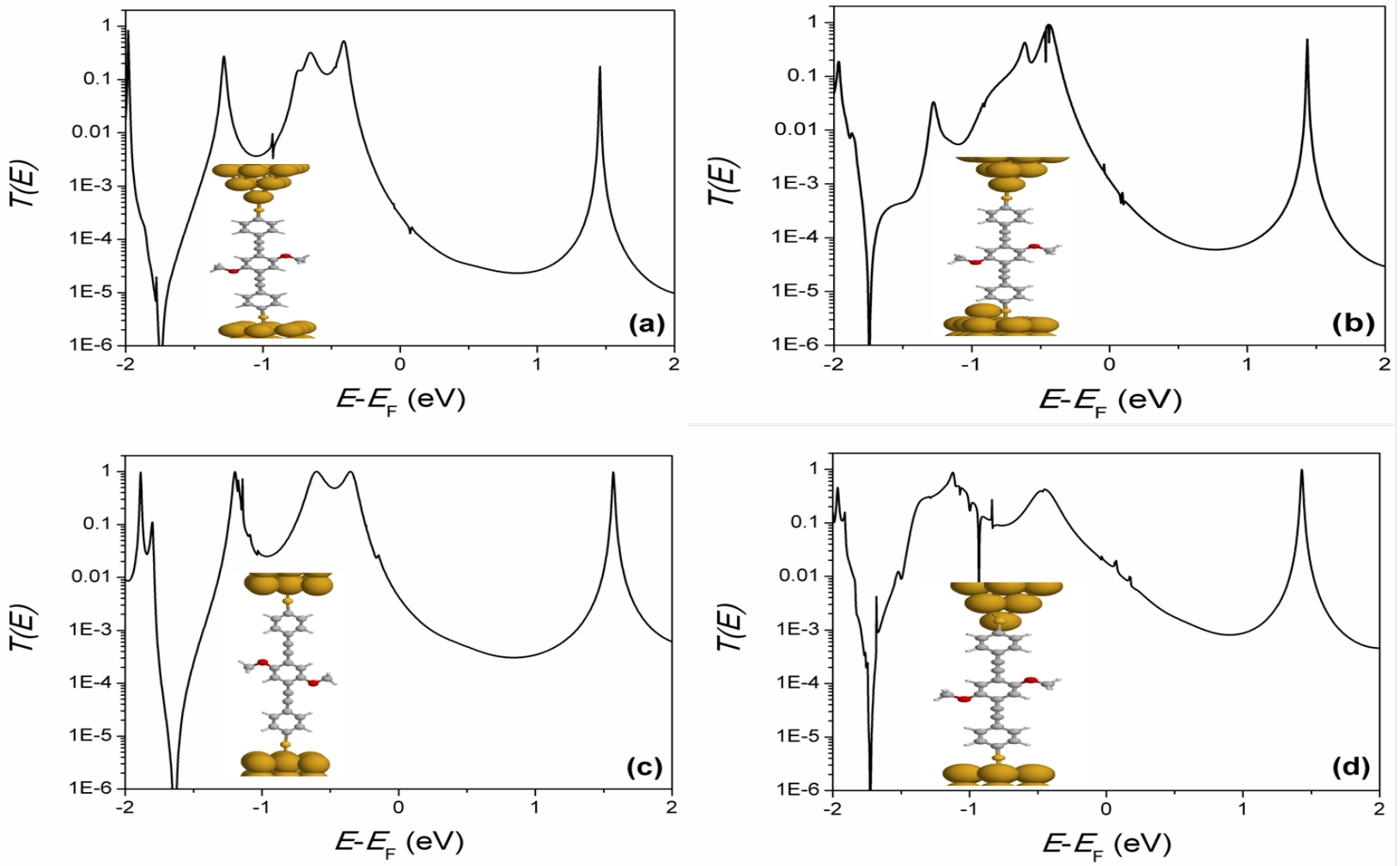

Figure S7. Zero bias transmission coefficient $T(E)$ against energy for four possible contact geometries of 1.(a) surface to tip, (b) tip to step, (c) surface to surface and (d) tip-step to surface.

Having proposed potential geometrical configurations for compound 1 for each of the conductance peaks seen in the experimental histograms we repeat these calculations for the other molecules 4, 5 and 2. While these molecules all have similar lengths, they differ in their contacting end groups and the side groups attached to the central phenyl ring. First we investigate the role of the side groups. Figure S8 shows a comparison between the transmission for the dithiol molecules $(1,2)$ with the methoxy side groups (Figure S8a) and the t-butyl groups (Figure S8b). The transmission curves are almost identical which agrees with the experimental observation that these molecules have similar 
conductance values. This suggests that for isolated molecules these side groups have no significant effect on the transport close to the Fermi energy. Their significance in this work lies in how they control the stacking of these molecules in the junction.
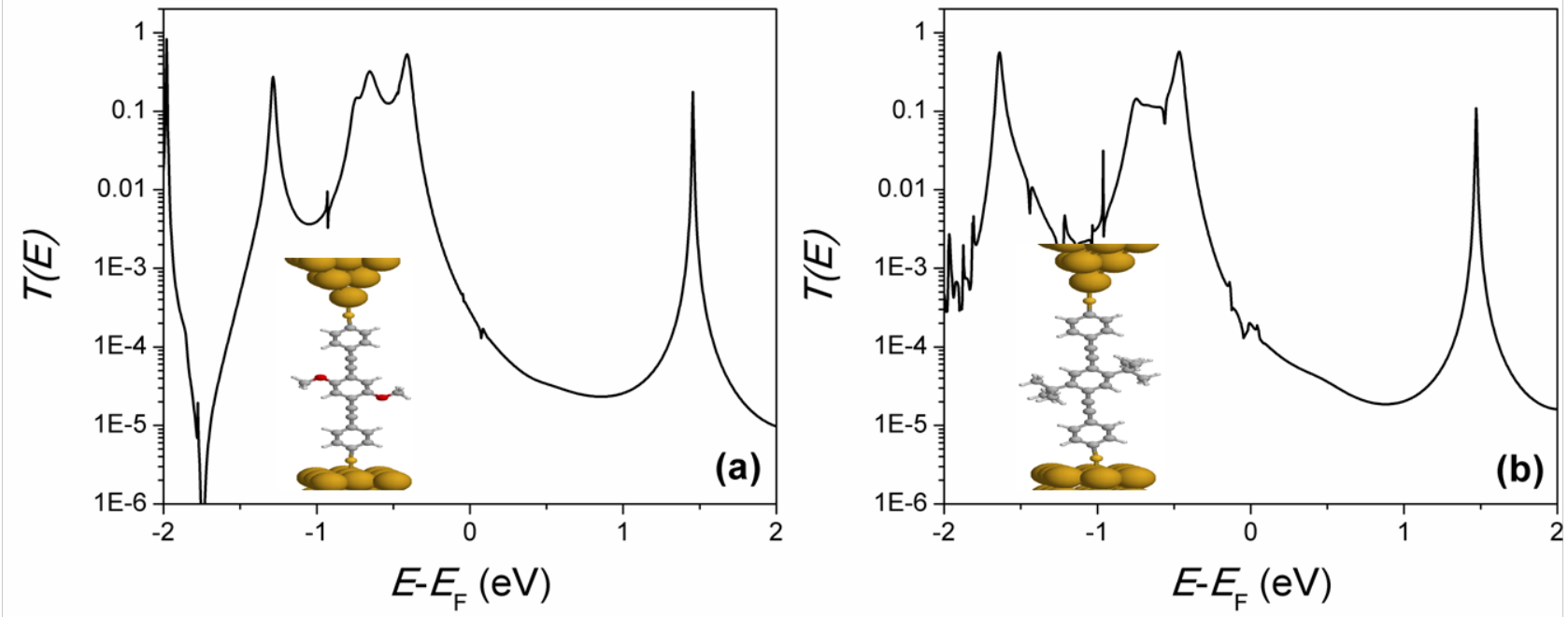

Figure S8. Comparison of side groups. Zero bias transmission through (a) 1 and (b) 2.

\section{Conductance corrections}

DFT typically underestimates the HOMO-LUMO gap in molecules, which is one reason why theory and experiment can disagree. One method which attempts to deal with this was developed by Quek et al.. ${ }^{14}$ Here we have implemented this approach (see reference 14 for a complete description of this method) to attempt to get better agreement with the experimental measurements. A comparison between the values using the unadjusted calculations and the Quek et al. approach can be seen in Table 1 (main paper). In these calculations the Fermi energy sits close to the HOMO resonance, so initially the ionization energy is computed for the isolated molecule (gas phase) and compared to the DFT-calculated HOMO energy. The resonances are then shifted by the difference between these two. The effects of the "mirror charge" are then included, which again shift the resonances. An example of this shift can be seen in Figure S9, which compares the original DFT transport (black line) with the adjusted (red line). The correction shifts the resonances so that the Fermi energy then lies in the middle of the HOMO-LUMO gap; this causes the computed conductance to decrease to values in better agreement with the experimental measurements. 


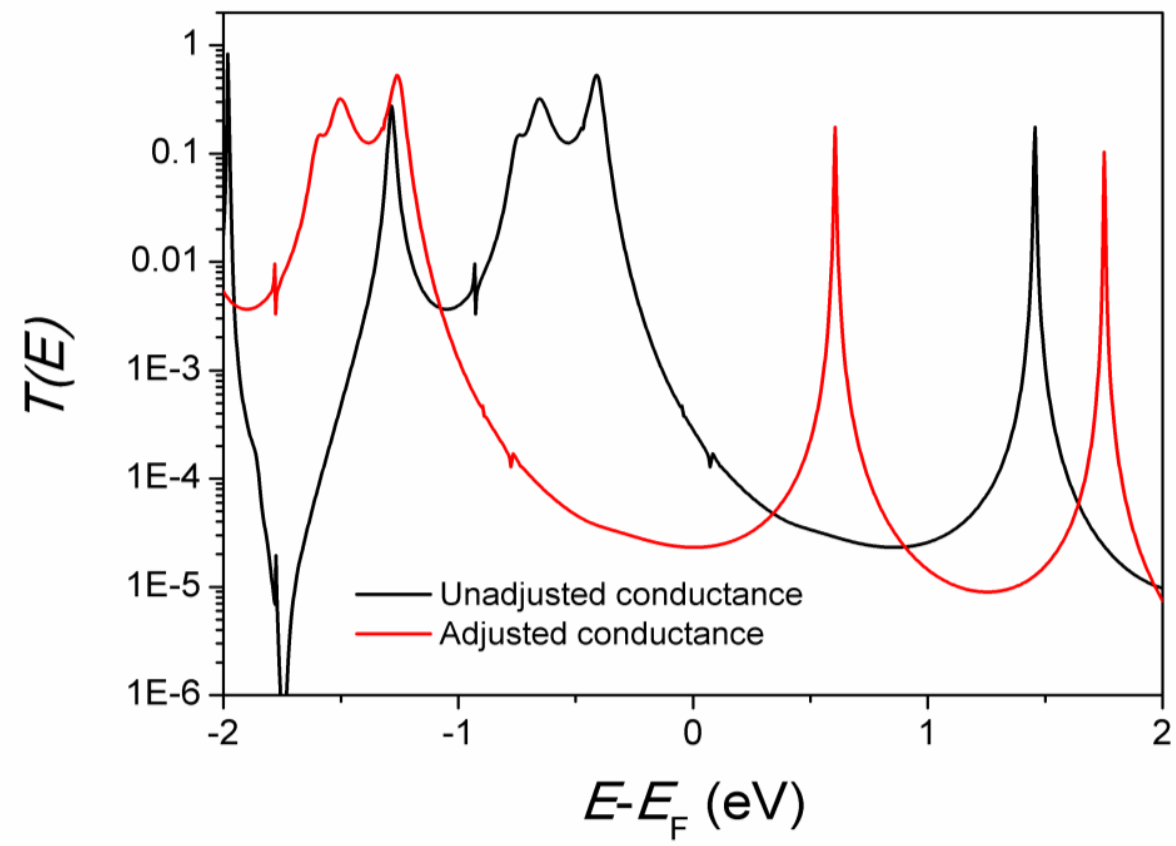

Figure S9. Comparison of unadjusted (black line) and adjusted (red line) ab initio transport calculations for molecule 1 .

\section{Discussion of the 0 rigin of the $\pi-1$ and $\pi-2$ Peaks}

Figure 1 of the main manuscript shows the resolution of two $\pi$-peaks ( $\pi$ - 1 and $\pi$-2) for compound 4 . The difference in break-off length between these two peaks is about $0.27 \mathrm{~nm}$ (Table 1) and figure S10. This difference in break-off distance between the $\pi-1$ and $\pi-2$ peaks is similar to that for the $A$ and $B$ groups. By analogy with the $A$ and $B$ groups this suggests that the $\pi-1$ and $\pi-2$ peaks also differ by the adsorption configuration, with $\pi$-2 involving surface coordination at a more transmissive ("step" or equivalent) site.

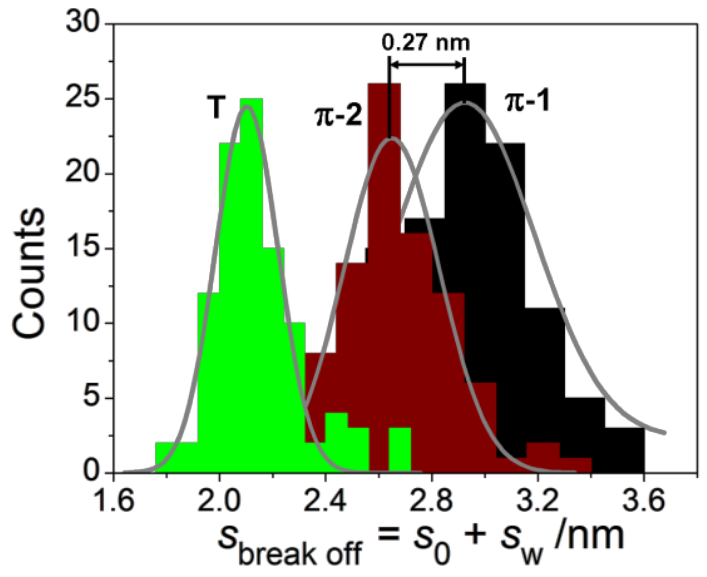

Figure S10. Break-off distances histograms for 4 for the T, $\pi$-2 and $\pi$ - 1 peaks. 


\section{References for the Supplementary Information}

(1) Haiss, W.; Wang, C. S.; Grace, I.; Batsanov, A. S.; Schiffrin, D. J.; Higgins, S. J.; Bryce, M. R.; Lambert, C. J.; Nichols, R. J. Nat. Mater. 2006, 5, 995-1002.

(2) Reck, C. E.; Winter, C. H. Organometallics 1997, 16, 4493-4496.

(3) Sheldrick, G. M. SHELXTL, version 6.14; Bruker-Nonius AXS, Madison, Wisconsin, U.S.A. 2003.

(4) Haiss, W.; Martin, S.; Scullion, L. E.; Bouffier, L.; Higgins, S. J.; Nichols, R. J. Phys. Chem. Chem. Phys. 2009, 11, 10831-10838.

(5) Haiss, W.; van Zalinge, H.; Higgins, S. J.; Bethell, D.; Hobenreich, H.; Schiffrin, D. J.; Nichols, R. J. J. Am. Chem. Soc. 2003, 125, 15294-15295.

(6) Wang, C. S.; Batsanov, A. S.; Bryce, M. R.; Martin, S.; Nichols, R. J.; Higgins, S. J.; Garcia-Suarez, V. M.; Lambert, C. J. J. Am. Chem. Soc. 2009, 131, 15647-15654.

(7) Haiss, W.; Martin, S.; Leary, E.; van Zalinge, H.; Higgins, S. J.; Bouffier, L.; Nichols, R. J. J. Phys. Chem. C 2009, 113, 5823-5833.

(8) Xu, B. Q.; Xiao, X. Y.; Tao, N. J. J. Am. Chem. Soc. 2003, 125, 16164-16165.

(9) Morita, T.; Lindsay, S. J. Am. Chem. Soc. 2007, 129, 7262-7263.

(10) Soler, J. M.; Artacho, E.; Gale, J. D.; Garcia, A.; Junquera, J.; Ordejon, P.; SanchezPortal, D. J. Phys.: Condens. Matter 2002, 14, 2745-2779.

(11) Perdew, J. P.; Zunger, A. Phys. Rev. B. 1981, 23, 5048-5079.

(12) Ulman, A. Chem. Rev. 1996, 96, 1533-1554.

(13) Rocha, A. R.; Garcia-Suarez, V. M.; Bailey, S.; Lambert, C.; Ferrer, J.; Sanvito, S. Phys. Rev. B. 2006, 73, 085414.

(14) Quek, S. Y.; Kamenetska, M.; Steigerwald, M. L.; Choi, H. J.; Louie, S. G.; Hybertsen, M. S.; Neaton, J. B.; Venkataraman, L. Nat. Nanotechnol. 2009, 4, 230-234. 